\title{
Key signaling pathways in thyroid cancer
}

\section{Miguel A Zaballos and Pilar Santisteban}

Instituto de Investigaciones Biomédicas 'Alberto Sols', Consejo Superior de Investigaciones Científicas (CSIC), Universidad Autónoma de Madrid (UAM), Centro de Investigación Biomédica en Red de Cáncer (CIBERONC), Instituto de Salud Carlos III (ISCIII), Madrid, Spain
Correspondence

should be addressed

to P Santisteban

Email

psantisteban@iib.uam.es

\begin{abstract}
Whole genome sequencing approaches have provided unprecedented insights into the genetic lesions responsible for the onset, progression and dedifferentiation of various types of thyroid carcinomas. Through these efforts, the MAPK and PI3K signaling cascades have emerged as the main activation pathways implicated in thyroid tumorigenesis. The nature of these essential pathways is highly complex, with hundreds of components, multiple points of crosstalk, different subcellular localizations and with the ability to potentially regulate many cellular processes. Small-molecule inhibitors targeting key kinases of these pathways hold great promise as novel therapeutics and several have reached clinical trials. However, while some remarkable responses have been reported, the development of resistance remains a matter of concern and limits the benefit for patients. In this review, we discuss the latest findings on the major components of the MAPK and PI3K pathways, including their mechanisms of activation in physiological and pathological contexts, their genetic alterations with respect to the different types of thyroid carcinomas and the more relevant drugs designed to block their activity.
\end{abstract}
Key Words
- MAPK
$\checkmark \mathrm{PI} 3 \mathrm{~K}$
- thyroid
- cancer
- signaling

\section{Introduction}

Thyroid cancer remains the most common endocrine malignancy worldwide and its incidence and mortality has increased steadily over the last four decades. Improvements in diagnostic techniques that allow a more efficient detection of small tumors may account in part for this increase, although a true rise in the occurrence of thyroid cancer is suggested by the findings that the number of tumors of larger size and that are detectable by palpation has also risen during this period (Lim et al. 2017). Thyroid carcinomas develop from two different cell types in the thyroid gland: follicular cells and parafollicular (C) cells. Follicular cells are epithelial cells that are responsible for iodine uptake and thyroid hormone synthesis (Colin et al. 2013), and from which arise $>90 \%$ of thyroid-derived carcinomas. Parafollicular
(C) cells produce and secrete the hormone calcitonin and generate $3-5 \%$ of thyroid-derived carcinomas, collectively known as medullary thyroid carcinomas (MTC), which are predominantly driven by activating mutations in the RET (rearranged during transfection) tyrosine kinase receptor (Cote et al. 2015).

Carcinomas derived from thyroid follicular cells can be subdivided into four main different types based on histological architecture and cellular morphology. Thyroid carcinomas that retain differentiated properties are termed well-differentiated thyroid carcinomas (WDTC) and include two main subtypes: papillary thyroid carcinoma (PTC) and follicular thyroid carcinoma (FTC). The two other main types are poorly differentiated thyroid carcinoma (PDTC) and anaplastic thyroid carcinoma
() 2017 Society for Endocrinology Printed in Great Britain 
(ATC), which constitute the most rare and aggressive forms of thyroid cancer. Although some evidence supports ATC arising de novo, it is generally accepted that it derives from accumulating mutations in pre-existing WDTC, with PDTC likely being an intermediate state in its progression (Wiseman et al. 2003a,b, Landa et al. 2016).

PTC is the most frequent form of differentiated thyroid carcinoma and accounts for $80-85 \%$ of all thyroid carcinomas. PTC can be classified into several variants, among the common of which are the classic variant (CV-PTC), the follicular variant (FV-PTC) and the tall cell variant (TCV-PTC). PTC is mostly related to mutations that activate the MAPK (mitogen-activated protein kinase) signaling pathway, such as RET, NTRK (neurotrophic receptor tyrosine kinase) and $A L K$ (anaplastic lymphoma kinase) gene rearrangements or RAS (rat sarcoma) and $B R A F$ (rapidly accelerated fibrosarcoma type-B) activating point mutations, which are almost always found in an exclusive manner, suggesting that oncogenic activation of one member of the pathway is sufficient to drive transformation (Kimura et al. 2003, Soares et al. 2003, Frattini et al. 2004). FV-PTC shares characteristics with PTC and FTC and is thought to be associated with both the activation of MAPK and PI3K (phosphatidylinositol 3-kinase) (Santarpia et al. 2010). PTC presents a low frequency of somatic mutations and has a good prognosis, with a 5-year overall survival of about 95\% (Hay et al. 2002). However, a subset of PTC correlates with tumor recurrence, local spreading and lymph node metastases and presents a worse prognosis.

FTC represents $10-15 \%$ of all the thyroid carcinomas. The main drivers of FTC are RAS mutations and
PAX8/PPAR $\gamma$ rearrangements. While RAS proteins can activate both the MAPK and PI3K pathways, the oncogenic variants of RAS have a lower flux through the former as compared with BRAFV600 mutations found in PTC and are likely more dependent on PI3K activation to initiate tumorigenesis. FTC also presents a good prognosis with a 5 -year overall survival of $91 \%$, although in the worst cases it courses with hematological spread and bone and lung metastases and presents a bad prognosis.

PDTC and ATC are rare and very aggressive thyroid carcinomas with a frequency of $6 \%$ and $1-2 \%$, respectively and have a dismal outcome with a respective mean survival time of 3.2 and 0.5 years from the time of diagnosis and with no available treatment options, especially for ATC. Mutations that activate both MAPK and PI3K signaling pathways can be detected in PDTC and ATC, along with mutations in genes that confer aggressiveness and increase the mutational burden in these tumors. These include TP53 and EIF1AX and also epigenetic modifiers or mutations in the TERT gene promoter. Loss of the expression of genes related to iodine transport and organification, including the sodium/iodide symporter (NIS) gene, also occurs frequently in these tumors and has a negative impact on prognosis, since the tumors can no longer accumulate iodide and therefore do not respond to radioactive iodine therapy. A summary of the characteristic features of the most common thyroid carcinomas is shown in Fig. 1.

In this review, we describe the main signaling pathways and driver oncogenes related to thyroid tumorigenesis, focusing on the MAPK and PI3K pathways, whose relevance as drivers of oncogenesis in the thyroid gland are clearly established.

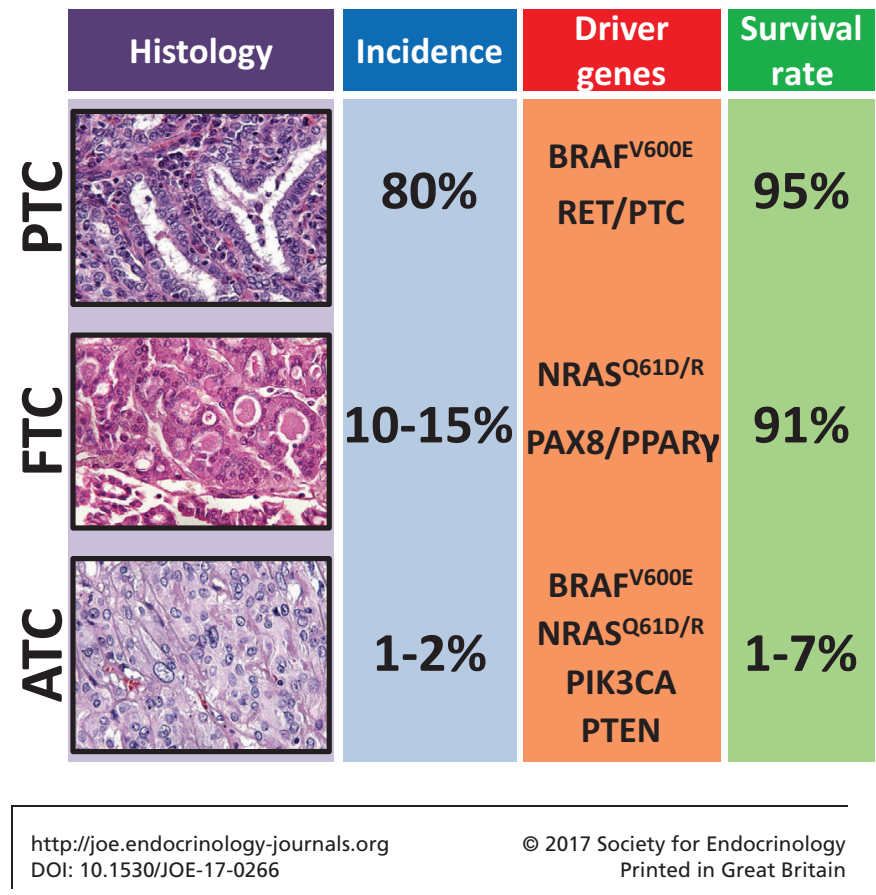

\begin{tabular}{|l}
\multicolumn{1}{c}{ Other } \\
features
\end{tabular}

\section{Figure 1}

Genetic and clinicopathological features of thyroid carcinomas. The main features of the most representative types of thyroid carcinomas, including PTC, FTC and ATC are shown. 40x magnification of histological sections are stained with hematoxylin and eosin. The 'driver genes' column shows the most frequent mutations associated with each type of thyroid carcinoma. The 'survival rate' column shows the 5-year overall survival rate. 


\section{The MAPK pathway}

The MAPK pathway is a conserved signal-transduction pathway that utilizes a series of protein kinases to transmit signals from the cell membrane to the nucleus. It controls a wide variety of essential cellular processes including proliferation, differentiation, motility and apoptosis. Hyperactivation of the MAPK pathway is implicated in various pathologies, including neurodegenerative and developmental diseases, diabetes and cancer (Krishna \& Narang 2008).

Activation of MAPK signaling is regulated by a central three-tiered kinase core comprising a MAPK kinase kinase, which activates a MAPK kinase that in turn activates a MAPK (such as JNK, ERK and p38). Pathway activation is triggered when external stimuli (e.g., growth factors and mitogens) bind to plasma membrane receptors, principally activated tyrosine kinase receptors, inducing receptor dimerization and autophosphorylation of residues that are recognized by adaptor proteins such as SHC1 (src homology 2 domain-containing transforming protein 1) and GRB2 (growth factor receptor-bound protein 2). In turn, adapter proteins recruit guanine triphosphate (GTP) hydrolyzing enzyme (GTPase) exchange factors (GEFs) such as SOS (son of sevenless), to promote guanine di-phosphate (GDP) to GTP exchange on RAS proteins. Once activated, RAS recruits RAF proteins to the plasma membrane for activation, which induces the sequential activation of MEK and ERK. Up to two hundred different effectors are activated by ERK in various cell compartments, such as cytoplasm, mitochondria, Golgi, endoplasmic reticulum and particularly the nucleus where it activates a suite of transcription factors mainly related to proliferation including c-FOS, c-JUN, c-MYC or ELK1. MAPK pathway activation is also controlled at multiple levels by positive and negative feedback regulation that modulates the duration and amplitude of the signals and also by different adaptor proteins that determine the subcellular localization of the three-tiered kinase core (Shaul \& Seger 2007). A representation of the MAPK pathway is depicted in Fig. 2.

Mutations in different components of the MAPK pathway have been found in more than half of all human cancers. Thyroid carcinoma is predominantly a MAPKdriven cancer and $\sim 70 \%$ of thyroid carcinomas are caused by mutations that activate this pathway. The primary mutations that give rise to thyroid carcinoma and are therefore considered driver mutations are $B R A F$ and $R A S$ point mutations and RET/PTC rearrangements, which

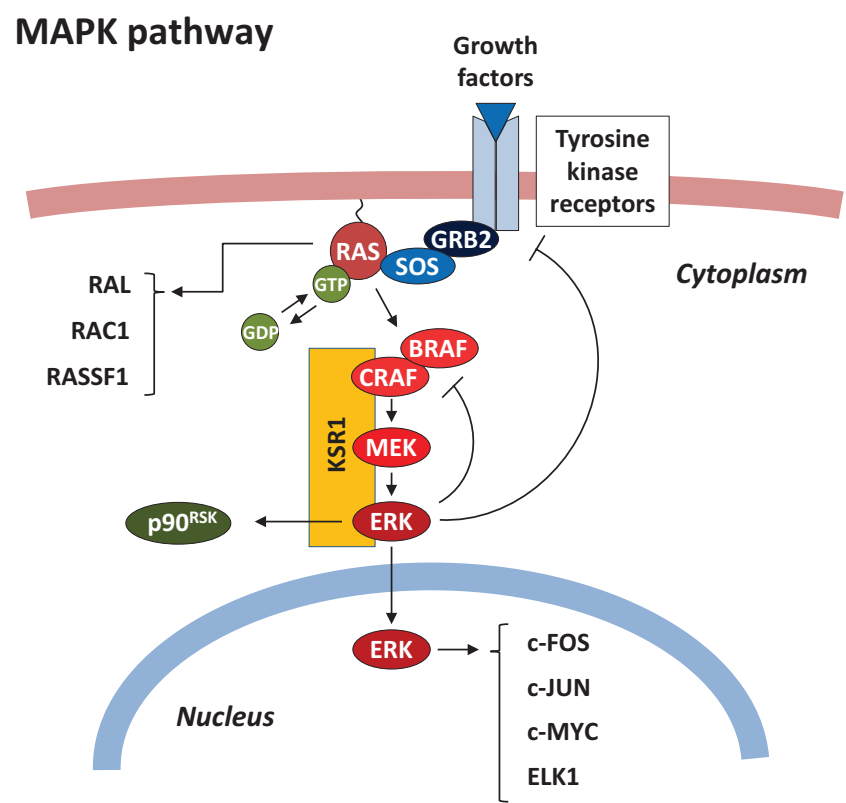

Figure 2

Overview of the MAPK pathway. Tyrosine kinase receptors are activated in response to binding of growth factors, allowing recruitment of adaptor and GEF proteins that promote GDP to GTP exchange on RAS proteins, eliciting their activation. RAS activates several downstream effectors including RAF proteins in a manner dependent on RAF phosphorylation and dimerization that leads to the sequential activation of MEK and ERK. This is facilitated by scaffolding proteins such as KSR1 that modulates activation of the pathway. Negative feedback circuits that uncouple RAS activation by the receptor and RAF dimerization switch-off the pathway. ERK promotes activation of downstream effectors both in the cytoplasm and in the nucleus, controlling different cellular processes. Arrows indicate activation $(\rightarrow)$ and truncated lines inactivation $(-1)$, the double arrow indicates a reversible state $(\rightleftarrows)$.

appear in an exclusive manner, reflecting the dependence of thyroid tumors on MAPK activation.

An increased understanding of the molecular mechanisms leading to the establishment and progression of thyroid tumors in the last years has guided the development and use of small kinase inhibitors against the major protein components of this signaling cascade. Some of these drugs have reached the clinic, and while the results obtained have been remarkable, they unfortunately rarely provide a durable response due to the emergence of resistance mechanisms that promote the recurrence of malignancies.

\section{Tyrosine kinase receptor rearrangements}

Rearrangements of different tyrosine kinase receptors that lead to constitutive activation of the MAPK pathway have been associated with the development of thyroid carcinoma. The most frequent and well characterized 
of these are translocations of RET/PTC, although NTRK and $A L K$ rearrangements have also been found at a lower prevalence. While these genetic events have the potential to activate other pathways such as the PI3K-AKT axis, their oncogenic potential in the thyroid has been mostly related to the activation of the MAPK pathway. Aberrant signaling induced by translocations of the receptors is represented in Fig. 3.

$\boldsymbol{R E T / P T C}$ rearrangements The RET receptor is a transmembrane tyrosine kinase receptor activated by members of the glial cell line-derived neurotrophic factor (GDNF) family, and it is required for the development, maturation and maintenance of different tissues such as kidney, nervous system or spermatogonial stem cells (Mulligan 2014). RET is also expressed in neural and neuroendocrine cell lineages, such as thyroid C cells.

Upon binding of ligands, RET dimerizes and undergoes autophosphorylation on intracellular tyrosine residues, allowing the recruitment of adaptor proteins and the activation of downstream pathways such as MAPK and PI3K, among others (Arighi et al. 2005). More than a dozen different $R E T / \mathrm{PTC}$ rearrangements have been found to be associated with thyroid cancer, the most frequent of which are RET/PTC1 and RET/PTC3, which represent 90\% of the total number of known rearrangements. RET/PTC1 and $R E T / \mathrm{PTC} 3$ are formed by fusion of the 3 ' terminal region of the RET gene to the 5' terminal region of $C C D C 6$ (coiled-coil domain containing gene 6) (Grieco et al. 1990) or NcoA4 (nuclear receptor co-activator gene 4) (Santoro et al. 1994) genes, respectively. The resultant chimeric proteins are thus formed by the C-terminal and kinase domains of RET and an N-terminal region from the partner gene, which provides a dimerization motif, rendering the protein constitutively active. RET/PTC translocations are more frequent in children and young adults (Nikiforov et al. 1997, Elisei et al. 2001) and have been associated with radiation exposure that triggers DNA double-strand breaks and RET gene illegitimate recombination with genes that are in close proximity during mitotic interphase (Nikiforova et al. 2000, Gandhi et al. 2010).

RET fusions are mainly associated with PTC (Nikiforov 2002), but can also be found in thyroid adenomas (Ishizaka et al. 1991), Hashimoto's thyroiditis (Wirtschafter et al. 1997) and other non-neoplastic lesions (Sapio et al. 2011). The high prevalence of RET/PTC in subclinical papillary microcarcinomas (Viglietto et al. 1995) and the exclusivity pattern with regards to other frequently mutated genes of the pathway strongly suggest that RET fusion is an early event during the onset of thyroid tumors. In addition, RET/PTC1 (Jhiang et al. 1996, Santoro et al. 1996) or RET/PTC3 (Powell et al. 1998) expression in the thyroid of transgenic mice generates PTC-like neoplasms. The association of RET/ PTC translocations with an aggressive phenotype is unclear. Expression of RET/PTC1 and RET/PTC3 in the rat thyroid cell line PCCl3 has been shown to decrease the expression of thyroid differentiation markers, such as the thyrotropin receptor (TSH-R), thyroperoxidase (TPO), NIS and thyroglobulin (TG) (Santoro et al. 1993, Trapasso et al. 1999, Wang et al. 2003). Dedifferentiation was shown to be mediated by the RAS-ERK pathway and to be dependent on the Y1062 residue in RET

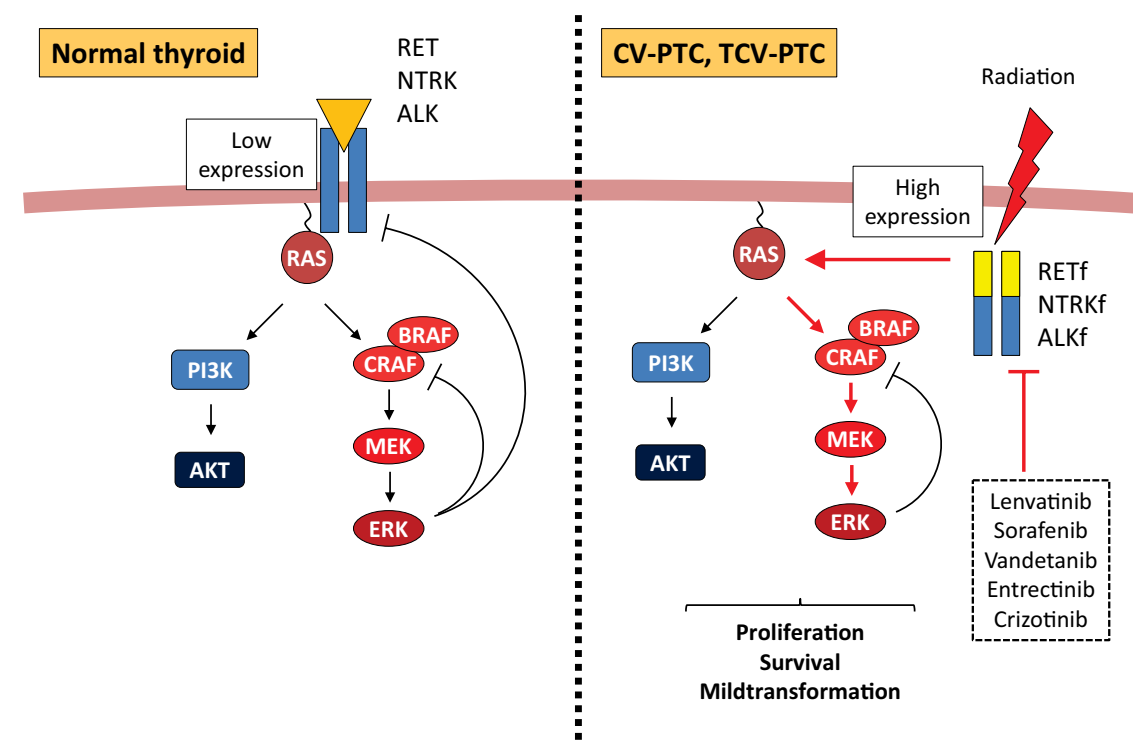

Figure 3

Tyrosine kinase receptor rearrangements in thyroid carcinomas. In normal thyroid tissue, the expression of RET, NTRK and ALK receptors is very low and binding of their agonists is required for activation of MAPK and PI3K downstream pathways (left). Exposure to radiation induces the formation of chimeric receptors aberrantly localized in the cytoplasm, with increased expression and constitutive kinase activity in the absence of receptor agonists (right). These genetic alterations are usually associated with the classic (CV-PTC) and tall cell (TCV-PTC) variants of PTC. Small kinase inhibitors against tyrosine kinase receptors are shown in dashed boxes. Arrows indicate activation $(\rightarrow)$ and truncated lines inactivation $(-1)$. Red arrows indicate increased flux through the pathway. 
(Knauf et al. 2003). Chronic (Santoro et al. 1993) but not acute (Wang et al. 2003) expression of RET/PTC in PCCl3 cells supports growth in the absence of thyroid-stimulating hormone, while induction of apoptosis by oncogene expression was observed in both experimental approaches (Castellone et al. 2003, Wang et al. 2003). Conversely, human PTC harboring RET/PTC translocations showed no differences in the expression of thyroid differentiation markers when compared with matched healthy tissue (Romei et al. 2008). While RET fusions have not been related to progression to PDTC or ATC, in a recent study using next-generation sequencing of 341 cancer genes from 117 patient-derived PDTCs and ATCs, RET/PTC fusions were found in $14 \%$ of PDTC, but were completely absent in ATCs (Landa et al. 2016).

No specific RET inhibitor is currently available; however, several small-molecule tyrosine kinase inhibitors (TKIs) developed to target other tyrosine kinase receptors, such as vandetanib (Carlomagno et al. 2002), lenvatinib (Okamoto et al. 2013) or sorafenib (Carlomagno et al. 2006), have been found to effectively inhibit RET in cultured cells and in xenograft models. As RET/PTC fusions are uncommon in advanced thyroid cancer, the effectiveness of drugs targeting RET/PTC in clinical trials is yet to be assessed.

NTRK rearrangements The NTRKs are members of the neurotrophin receptor family of receptor tyrosine kinases that are activated by different neurotrophic factors including NGF (nerve growth factor). Upon ligand binding, NTRKs dimerize and autophosphorylate, leading to the recruitment of adaptor and signaling proteins and the activation of downstream pathways including MAPK and PI3K. NTRKs play an essential role in the development and the maturation of the central and peripheral nervous systems through regulation of proliferation, differentiation and survival of sympathetic and nervous neurons (Kaplan \& Miller 2000).

Rearrangement of NTRK1 with different partner genes such as TPM3 (Butti et al. 1995), TPR (Greco et al. 1992) or TFG (Greco et al. 1995), which encode proteins containing coiled-coil domains, generates NTRK1 fusion proteins with constitutive tyrosine kinase activity. NTRK3 gene rearrangements with ETV6 and RBPMS have also been found in PTC (Cancer Genome Atlas Research Network 2014, Leeman-Neill et al. 2014). The Cancer Genome Atlas (TCGA) network reported a low incidence of NTRK rearrangements $(1.2 \%)$ in sporadic PTC
(Cancer Genome Atlas Research Network 2014). Similar to what is found with RET/PTC fusions, theincidence ofNTRK3 rearrangements is high in radiation-exposed populations (Leeman-Neill et al. 2014), and the predisposition of thyroid cells to NTRK rearrangements has also been rationalized by the proximity of fusion partner genes during interphase (Roccato et al. 2005). Expression of the TPM3/NTRK1 fusion in PCCl3 cells blocks iodine uptake and thyroperoxidase expression, although fails to confer a transformed phenotype (Santoro et al. 1993). The role of NTRK gene fusions as drivers of thyroid tumorigenesis is supported by the finding of thyroid hyperplasia and thyroid carcinomas in transgenic mice expressing TPR/NTRK1 under the control of the thyroglobulin promoter (Russell et al. 2000).

NTRK gene fusions have emerged as thyroid cancer targets and different drugs have been developed that can effectively inhibit NTRK activity across several tumor histologies (Amatu et al. 2016). In a recent case study, a partial response to the pan-TRK inhibitor entrectinib was reported in a patient with metastatic colorectal carcinoma harboring a NTRK rearrangement (Sartore-Bianchi et al. 2016). Several clinical basket trials targeting carcinomas with NTRK fusions are ongoing, some of which include patients with NTRK translocations and advance thyroid carcinoma.

ALK rearrangements ALK is a tyrosine kinase receptor that was originally identified as part of a novel chimeric protein in ALCL (anaplastic large cell lymphoma) cell lines (Morris et al. 1994). Based on overall homology, ALK is grouped within the insulin receptor superfamily (Iwahara et al. 1997, Morris et al. 1997). Results from analysis of $A L K$ expression during mouse embryogenesis (Vernersson et al. 2006) and in different in vitro studies (Souttou et al. 2001, Motegi et al. 2004) point to a role for ALK in neuronal development. Its mechanism of activation is similar to that of other tyrosine kinase receptors and, upon ligand binding, ALK dimerizes and undergoes autophosphorylation, which activates downstream pathways including RAS-MAPK (Souttou et al. 2001), PI3K-AKT (Bai et al. 2000) and JAK/ STAT3 (Chiarle et al. 2005). ALK rearrangements have been detected in different tumor types such as ALCL (Morris et al. 1994), NSCLC (non-small-cell lung cancer) (Soda et al. 2007) and IMT (inflammatory myofibroblastic tumor) (Griffin et al. 1999), among others. Activating point mutations and increased copy number are also frequently found in several human malignancies. Interestingly, some 
of these mutations have been related to resistance to ALKspecific inhibitors (Choi et al. 2010, Ou et al. 2014).

$A L K$ rearrangements with different partner genes can be found at low frequency in thyroid carcinomas (Cancer Genome Atlas Research Network 2014, Landa et al. 2016). As in other gene rearrangements, the prevalence of $A L K$ fusions seems to be higher in radiation-exposed populations (Hamatani et al. 2012). ALK rearrangements have been found to be associated with PTC, PDTC and ATC, but are absent in FTC, and occur in an exclusive manner with regards to other driver mutations activating MAPK signaling, suggesting that they are sufficient to trigger thyroid tumorigenesis. A common ALK fusion, STRN/ALK, leads to the activation of ALK and MEK-ERK, and increases cell proliferation and transformation in vitro and in vivo (Kelly et al. 2014), supporting the role of $A L K$ rearrangements as early drivers of thyroid carcinogenesis. Its association with an aggressive phenotype is, however, not clear. While some authors have reported $A L K$ fusions with higher prevalence in PDTC and ATC as compared with PTC (Kelly et al. 2014), others were unable to find any $A L K$ translocation in different types of aggressive thyroid carcinomas (Chou et al. 2015). ALK-activating point mutations have also been found in ATC tumor samples, leading to constitutive kinase activity, MAPK and PI3K activation and transformation when expressed in NIH3T3 cells (Murugan \& Xing 2011).

Several tyrosine kinase inhibitors targeting ALK kinase activity have been developed with encouraging results in clinical trials, although responses were not durable due to the aforementioned resistance phenomena. Nevertheless, in a case study of a patient with ATC harboring an $A L K$ rearrangement, the ALK inhibitor crizotinib yielded a remarkable response with a $90 \%$ reduction of metastatic lung lesions (Godbert et al. 2015).

\section{RAS oncogenes}

RAS proteins are small GTPases that coordinate many different signaling processes of the cell via activation of a broad range of effectors. They normally cycle between a GTP-bound active state, promoted by GEFs and a GDP-bound inactive state, which is facilitated by the stimulation of GTP hydrolysis by GTPase-activating proteins (GAPs) (Bos et al. 2007). Once activated, RAS recruits downstream effector proteins, promoting their activation. At least 11 RAS effector families have been described so far, and functional studies have indicated that 6 of them contribute to RAS-dependent cancer initiation or maintenance. The most studied and the most commonly related to thyroid carcinogenesis are the RAF kinases, which activate MEK and ERK. The high frequency of mutations in BRAF and the exclusivity of mutations activating RAS and BRAF strongly suggest that BRAF is a key driver of RAS-driven carcinogenesis. However, BRAF activation does not simply mimic the activation of RAS, indicating that activation of other RAS effectors plays a role in RAS oncogenic activity. The second most validated RAS effectors are p110 catalytic subunits $(\alpha, \beta$ and $\gamma$ subunits) of class1 PI3Ks, which have been proven to be essential for RAS-driven tumorigenesis in some tumor types (Gupta et al. 2007). Other RAS effectors related to RAS-driven carcinogenesis include RAL (Ras-like protein), RAC1 (Ras-related C3 botulinum toxin substrate 1) and RASSF1 (Ras association domain family 1).

The RAS family comprises three main isoforms, namely $H, K$ and NRAS, encoded by separate genes. All RAS isoforms present a highly conserved domain structure that includes the switch 1 and switch 2 regions, which are involved in the activation state of the protein, and an effector domain that is involved in the interaction with effector proteins. As its name suggests, the C-terminal hypervariable region (HVR), which is responsible for membrane binding, largely differs between isoforms and is thought to determine functional isoform specificity. Accordingly, it has been reported that the different isoforms are tethered to specific domains of the plasma membrane and to different cytoplasmic organelles, potentially allowing signaling specificity for nearby effectors (Prior \& Hancock 2012). Their high homology initially suggested overlapping functions for RAS isoforms; however, early reports already pointed to specialized functions for each different isoform. The most striking example of this is the finding that although single $H$ and NRas and double knockout mice develop normally, KRas-knockout mice are not viable (Umanoff et al. 1995, Koera et al. 1997, Esteban et al. 2001).

$R A S$ is the most frequently mutated oncogene in cancer and is activated in one-third of all human tumors (Bos 1988). RAS proteins can be activated by single base missense mutations, usually at the residues G12, G13 or Q61 (in 98\% of the cases), which impair intrinsic and GAP-stimulated GTP hydrolysis and favor the formation of persistently GTP-bound RAS and constitutive activation. Many tumor types seem to be associated with mutations in a specific $R A S$ gene. Accordingly, KRAS is the most frequently mutated isoform in human carcinomas (86\% of RAS-driven carcinomas) and is 
especially common in carcinomas of endocrine origin, followed by NRAS (11\% of RAS-driven cancers), which is associated more with hematopoietic tumors, and finally HRAS, which is relatively rare (3\% of RAS-driven cancers). Interestingly, each isoform has a distinctive codon mutation signature that is similarly associated with specific tissue and tumor types (Prior et al. 2012). Although the functional differences between the RAS isoforms remain poorly understood, it has been reported that activation of downstream effectors as well as the regulation of cellular processes differ between isoforms. For example, KRAS is more prone to activate the protein kinase CRAF and the GTP-binding protein RAC, whereas HRAS more potently activates PI3K (Yan et al. 1998, Walsh $\&$ Bar-Sagi 2001). This preferential activation is reflected in the consequent physiological responses they activate: KRAS induces proliferation while NRAS has been shown to confer apoptosis resistance in a mouse model of colon carcinoma (Haigis et al. 2008).

The relationship between RAS mutations and thyroid cancer was established almost 30 years ago (Suarez et al. 1988). RAS mutations can be found in all stages of differentiation in thyroid tumors, from benign thyroid lesions such as follicular adenomas, to WDTC such as FTC and FV-PTC, as well as in the aggressive PDTC and ATC forms. The high frequency of RAS mutations in follicular adenomas suggests a role for aberrant RAS activation as an early event in thyroid tumorigenesis (Esapa et al. 1999). Several lines of evidence indicate that follicular adenomas harboring RAS mutations are the precursor lesions of FTC, with RAS activating point mutations as the most frequent genetic lesions. However, these events are less frequent in PTC and are almost exclusively associated with the FV-PTC form (Zhu et al. 2003). RAS mutations are very frequent in PDTC and ATC, supporting a role for RAS in the progression to aggressive forms of thyroid carcinomas. ATCs accumulate additional mutations such as TP53 mutations, which confer aggressiveness, while at the same time maintaining RAS mutations. Co-occurrence of RAS and TERT (telomerase reverse transcriptase) promoter mutations is also frequent in ATC, while RAS and EIF1AX mutations are frequently found together both in PDTC and ATC. In both cases, these additional mutations are associated with a worse prognosis than for tumors harboring only RAS mutations (Landa et al. 2016). Interestingly, oncogenic RAS expression in PCCl3 cells induces genomic instability that could favor the accumulation of additional mutations, allowing progression to advanced thyroid carcinomas (Saavedra et al. 2000). Altogether, these findings suggest that RAS mutations predispose to malignancy and progression to aggressive undifferentiated tumors. The impact of $R A S$ mutations in thyroid carcinomas is represented in Fig. 4.

While other tumor types are usually associated with mutations in a specific RAS isoform, mutations in all RAS isoforms can be detected in thyroid tumors, with NRAS mutations at codon 61 being by far the most frequent (Vasko et al. 2003). Whereas oncogenic KRAS and HRAS expression in the thyroid of transgenic mice fails to recapitulate human thyroid tumorigenesis, and presents only minor alterations such as mild proliferation, the equivalent expression of oncogenic NRAS generates follicular adenomas that progress to FTC and PDTC with

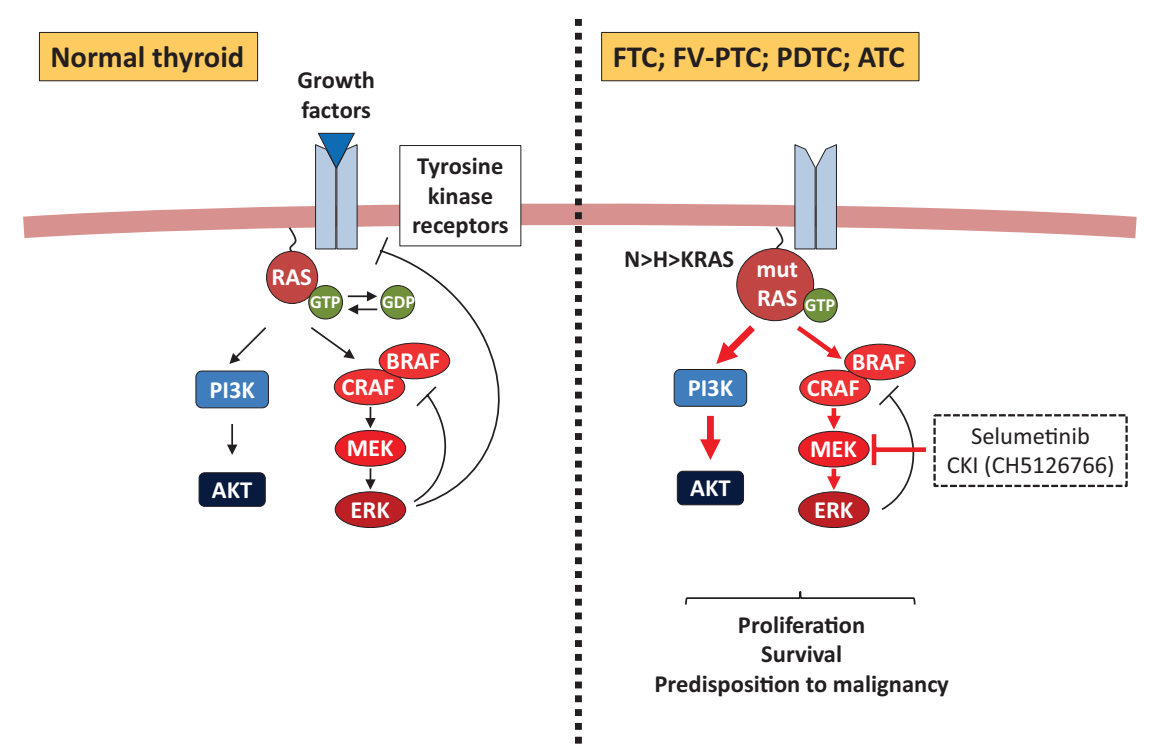

Figure 4

Ras mutations in thyroid carcinoma. In normal thyroid tissue, RAS proteins mediate the activation of tyrosine kinase receptors (left). NRAS is the most frequently mutated isoform, followed by HRAS and KRAS. The mutant forms of RAS (mutRAS) are active in the absence of extracellular stimuli and are able to activate MAPK and PI3K pathways, the latter with greater strength (right). RAS mutations are found associated with FTC, FV-PTC, PDTC and ATC. Since no inhibitors used to directly target RAS are available, the figure shows the small kinase inhibitors that target the downstream effector MEK in dashed boxes. Both MEK and BRAF inhibitors have been used against RAS mutant tumor cells in various studies. Arrows indicate activation $(\rightarrow)$ and truncated lines inactivation $(-1)$, the double arrow indicates a reversible state $(\rightleftarrows)$. Red arrows indicate increased flux through the pathway. 
distant metastases (Vitagliano et al. 2006). Overall, these results underscore the role of the NRAS isoform in thyroid tumorigenesis.

Given the importance of RAS as a driver of human carcinogenesis, great efforts have been made in the last three decades to impair oncogenic RAS signaling. Although many different strategies have been developed, RAS is still traditionally considered a 'non-druggable' target. Accordingly, GTP competitors were found to be ineffective due to the high affinity of the protein for GTP and the high ratio of GTP to GDP in the cell. Ras binding to the inner part of the membrane is required for its activation and is promoted by addition of farnesyl groups in the HVR region of the protein. The enzyme responsible for Ras farnesylation has been characterized; however, the use of drugs inhibiting farnesyl transferase was also ineffective since alternative mechanisms can result in RAS membrane anchoring. Because of this, current strategies are focused on the inhibition of downstream effectors of the pathway, such as BRAF and MEK (Cox et al. 2014).

\section{RAF family}

RAF proteins are a family of serine/threonine kinases that link RAS to the activation of the MAPK pathway. RAF1 (or CRAF) was the first family member to be described as a homolog of the viral RAF oncogene (Rapp et al. 1983). Subsequently, two other mammalian paralogues were identified and named BRAF (Ikawa et al. 1988) and ARAF (Huleihel et al. 1986). Upstream activation of RAF is elicited by RAS proteins, although additional factors are required for RAF maturation and activation. RAS-GTP associates with RAF and promotes RAF anchoring to the plasma membrane, a key step for RAF activation. Other proteins are also required to tether together the MAPK components, such as KSR (kinase suppressor of Ras) and are required for RAF activation. RAS binding and membrane recruitment induces RAF dimerization and phosphorylation in several residues that are important for its activation, but the mechanism remains poorly understood. Although homodimers can be formed, the BRAF/CRAF heterodimer shows the highest activity. Catalytically inactive BRAF can also promote signaling through dimerization with CRAF, which is relevant to therapies directed against BRAF kinase activity. BRAF shows a higher basal kinase activity than CRAF and ARAF, which require an additional phosphorylation at their N-terminal domains for full activation. RAF proteins activate MEK1 and MEK2 by phosphorylating their activation loops (Lavoie \& Therrien 2015).
$B R A F$ mutations have been found in a wide variety of tumor types and occur with high frequency in metastatic melanoma and PTC. Oncogenic CRAF activation has also been reported, albeit at a lower rate, and $A R A F$ mutations are very rare in human tumors. The most common BRAF mutation, accounting for $95 \%$ of the total, is a V600E amino acid substitution (BRAFV600) in the activation loop, promoting constitutive activation independent of RAS and with no requirement for dimerization. The V600E mutation also increases the kinase activity up to 500-fold as compared with wild-type BRAF. In physiological conditions, RAS-ERK signaling is tightly controlled by negative feedback mechanisms. Activated ERK phosphorylates RAF in a series of specific residues leading to impaired RAS binding and disruption of CRAFBRAF complexes (Dougherty et al. 2005, Ritt et al. 2010). As mutant BRAFV600E signals as a monomer, the negative feedback loop is inactive and leads to an increased signaling output of the pathway.

BRAF ${ }^{600 E}$ is the most common mutation in thyroid tumors. It has been detected in PTC, PDTC and ATC, but it is absent in FTC and in benign lesions. The frequency of BRAF mutations varies among the different subtypes of PTC; it is highly frequent in TCV-PTC and classic PTC but rare in FV-PTC. The presence of BRAF mutations in papillary microcarcinomas (Nikiforova et al. 2003) suggests that it is an initiating event in thyroid tumorigenesis. Furthermore, BRAF mutations rarely overlap with other driver oncogenes such as RAS or RET/PTC (Kimura et al. 2003, Soares et al. 2003). The role of BRAF in thyroid transformation has been clearly established both in vitro and in vivo. BRAFV600E conditional expression in rat thyroid cells induces DNA synthesis, apoptosis, dedifferentiation and chromosomal instability (Mitsutake et al. 2005), whereas BRAFV600 expression in the thyroid of transgenic mice promotes PTC that dedifferentiates to PDTC (Knauf et al. 2005). A role for BRAF mutations in the progression to undifferentiated carcinomas is also suggested by the co-existence of PTC and PDTC or ATC regions in the same tumor, both expressing mutant BRAF (Nikiforova et al. 2003).

BRAF mutations are associated with poor prognostic factors such as extrathyroidal extension, lymph node metastases, advanced stage, greater predilection to develop iodine-131 resistance and recurrent disease (Xing et al. 2013, 2015). Different studies have shown that BRAFV600E expression correlates with an increase in processes related to metastasis such as invasion, angiogenesis or extracellular matrix remodeling. Moreover, silencing of several tumor

Published by Bioscientifica Ltd. 
suppressor genes by promoter methylation is increased in BRAFV600E-harboring tumors, including TIMP3 (tissue inhibitor of matrix metalloproteinase-3), DAPK (deathassociated protein kinase) or $R A R \beta 2$ (retinoic acid receptor $\beta 2$ ) (Hu et al. 2006, Hou et al. 2011). In addition, BRAF ${ }^{600 E}$ expression can induce dedifferentiation of thyroid cells in vitro, with loss of expression of NIS, TG and TPO (Mitsutake et al. 2005, Riesco-Eizaguirre et al. 2006), which are also reduced in human PTC harboring BRAFV00e (Durante et al. 2007). Data from the TCGA network surveying a large panel of PTC confirmed that PTC with BRAFV60e mutations are associated with a dedifferentiation state and higher ERK activation than tumors harboring RAS mutations. This sustained and high flux through the pathway has important consequences for the behavior of the tumor. For instance, co-occurrence of BRAF and TERT promoter mutations synergistically increase the aggressiveness of the tumor. The TERT gene codes for the reverse transcriptase of the telomerase complex, which participates in maintaining the length of telomere ends required for continuous cell replication and immortalization (Nakamura et al. 1997). Increased TERT activity has been reported in different types of cancer. Two frequent and mutually exclusive mutations in the TERT promoter, $\mathrm{C}>\mathrm{T}$ at $-124 \mathrm{bp}$ (termed C228T) and $\mathrm{C}>\mathrm{T}$ at $-146 \mathrm{bp}$ (termed C250T) upstream from the translation start site were initially described in melanoma and recently in other carcinomas such as thyroid cancer. These mutations promote a 2 - to 4 -fold increase in the expression of TERT, ostensibly due to the generation of de novo binding sites for ETS transcription factors downstream of the MAPK pathway (Horn et al. 2013, Huang et al. 2013). TERT promoter mutations are found at a relatively low prevalence in PTC (around 11\%), but this increases in metastatic PTC, PDTC (30-40\%) and ATC (30-70\%) (Landa et al. 2013, Liu et al. 2013, Vinagre et al. 2013). Interestingly, TERT promoter mutations have been reported at a high frequency in distant but not in lymph node metastases, and when found together with BRAF mutations, especially in advanced thyroid carcinomas, they associate with more aggressive clinicopathological features than single BRAF or TERT mutations (Shi et al. 2015, Melo et al. 2017).

Other BRAF point mutations have been described at a much lower prevalence. For example, the K601E amino acid substitution has been detected in benign thyroid adenomas (Soares et al. 2003) and FV-PTC (Trovisco et al. 2004). Interestingly, tumors bearing BRAFK601E show a RAS-like behavior (Cancer Genome Atlas Research Network 2014) and give rise to follicular patterned lesions but do not result in PTC. The mechanism responsible for these differences remains unknown.

In addition to point mutations, BRAF activation by intrachromosomal inversion with the AKAP9 gene is reported to be related to radiation-induced PTC. Chromosomal translocation generates a constitutively active chimeric protein that maintains the kinase domain of BRAF but lacks the N-terminal autoinhibitory domain (Ciampi et al. 2005). BRAF rearrangements with different fusion genes have also been reported by The Cancer Genome Atlas project (Cancer Genome Atlas Research Network 2014).

Given the high prevalence of BRAF-activating mutations in human tumors, great efforts have been made in developing drugs that target BRAF. Initially described as a BRAF inhibitor, sorafenib was subsequently found to inhibit many other tyrosine kinases such as CRAF, VEGF (vascular endothelial growth factor) 1 and 3 receptors, PDGF (platelet-derived growth factor) receptor or RET kinases. Indeed, sorafenib was the first multikinase inhibitor approved by the FDA for the treatment of advanced thyroid cancer based on a phase III clinical trial that reported a significant increase in progressionfree survival: 10.8 months in the sorafenib group vs 5.8 months in the placebo group (Brose et al. 2014). However, the development of resistance after 1 or 2 years is almost inevitable in the majority of patients who show partial response or stabilization of the disease.

Lenvatinib is a multitargeted tyrosine kinase inhibitor of VEGF 1-3 receptors and other pro-oncogenic receptors including FGF (fibroblast growth factor) 1-4 receptors, PDGF receptor alpha and RET and KIT receptors. Lenvatinib is indicated in the EU and the USA for the treatment of locally recurrent or metastatic progressive, radioiodine-refractory differentiated thyroid cancer. Results of a phase III clinical study showed that lenvatinib improved progression-free survival and overall response rate compared with placebo (Schlumberger et al. 2015).

The effectiveness of drugs targeting different components of the MAPK pathway is largely dependent on their ability to inhibit ERK phosphorylation in a sustained manner. The TCGA project revealed that RAS and BRAF mutations confer distinct features to the tumor cells. Signaling through the pathway is higher and more durable in BRAF than in RAS mutant tumors, ostensibly due to the lack of action of negative feedback regulatory circuits in the former (Cancer Genome Atlas Research Network 2014). This has an impact in the response to
Published by Bioscientifica Ltd 
drugs aimed to impair signaling through the MAPK pathway. Accordingly, MEK tyrosine kinase inhibition by selumetinib was shown to restore or increase iodine uptake in metastatic lesions of patients with advanced thyroid cancer refractory to radioiodine treatment, having greater effectiveness in patients with NRAS mutations than in those with BRAF mutations (Ho et al. 2013). The authors of this study posited that a greater effect could be achieved with a stronger and more sustained inhibition of MAPK signaling. This was proved to be correct by the same authors in a recent study showing that CKI (CH5126766), an allosteric MEK inhibitor that achieves a more prolonged inhibition of the pathway by preventing MEK phosphorylation, yielded greater iodine uptake in mice with BRAFV600E-driven thyroid tumors (Nagarajah et al. 2016).

A representation of oncogenic BRAFV600E signaling in thyroid carcinomas is shown in Fig. 5.

\section{The PI3K pathway}

The PI3K family constitutes a large family of conserved proteins that control a myriad of cellular processes such as cell growth, proliferation, survival and motility (Cantley 2002). While many different systems of activation of PI3K exist, which are dependent on the class and the PI3K variant, the canonical activation of the pathway can be described as follows: in the absence of upstream activators, binding of the regulatory subunit maintains the catalytic subunit in a basal state; receptor activation promotes autophosphorylation of tyrosine residues that are recognized by adaptor proteins such as IRS (insulin receptor substrate) 1 and 2, recruiting PI3K heterodimers close to their lipid substrates in the plasma membrane. PI3Ks transmit their signal by phosphorylating phosphatidylinositol-4,5-bisphosphate to generate phosphatidylinositol-3,4,5-trisphosphate (PIP3), a plasma membranelipid second messenger that promotes activation of proteins with pleckstrin homology $(\mathrm{PH})$ domains such as PDK1 (phosphoinositide-dependent kinase 1) or AKT. Different phosphatases exercise negative control of the pathway, especially PTEN (phosphatase and tensin homolog deleted on chromosome 10), which opposes PI3K function by promoting PIP3 dephosphorylation. The mechanism of activation of the PI3K pathway is depicted in Fig. 6. Deregulation of the pathway has been associated with various diseases including cancer. In thyroid cancer, mutations in different components of the PI3K pathway are rare in WDTC but have a remarkable prevalence in PDTC and ATC, suggesting a role for PI3K activation in the progression to undifferentiated carcinomas.

\section{The PI3K family of proteins}

There are three different classes of PI3K proteins categorized by their lipid substrate specificity and the sequence homology of the catalytic subunit. Class 1 is the most studied and comprises two different subclasses. Class $1 \mathrm{~A}$ proteins are heterodimers formed by the $\mathrm{p} 110 \alpha$, $\mathrm{p} 110 \beta$ or $\mathrm{p} 110 \delta$ catalytic subunits and one of five different p85 regulatory subunits $(\mathrm{p} 85 \alpha, \mathrm{p} 55 \alpha, \mathrm{p} 50 \alpha, \mathrm{p} 85 \beta$ and p55 $\chi$ ) (Vanhaesebroeck et al. 2010). They are activated by tyrosine kinase receptors, although p110 $\beta$ can also be activated by $\mathrm{G}$ protein-coupled receptors. Class $1 \mathrm{~B}$ protein

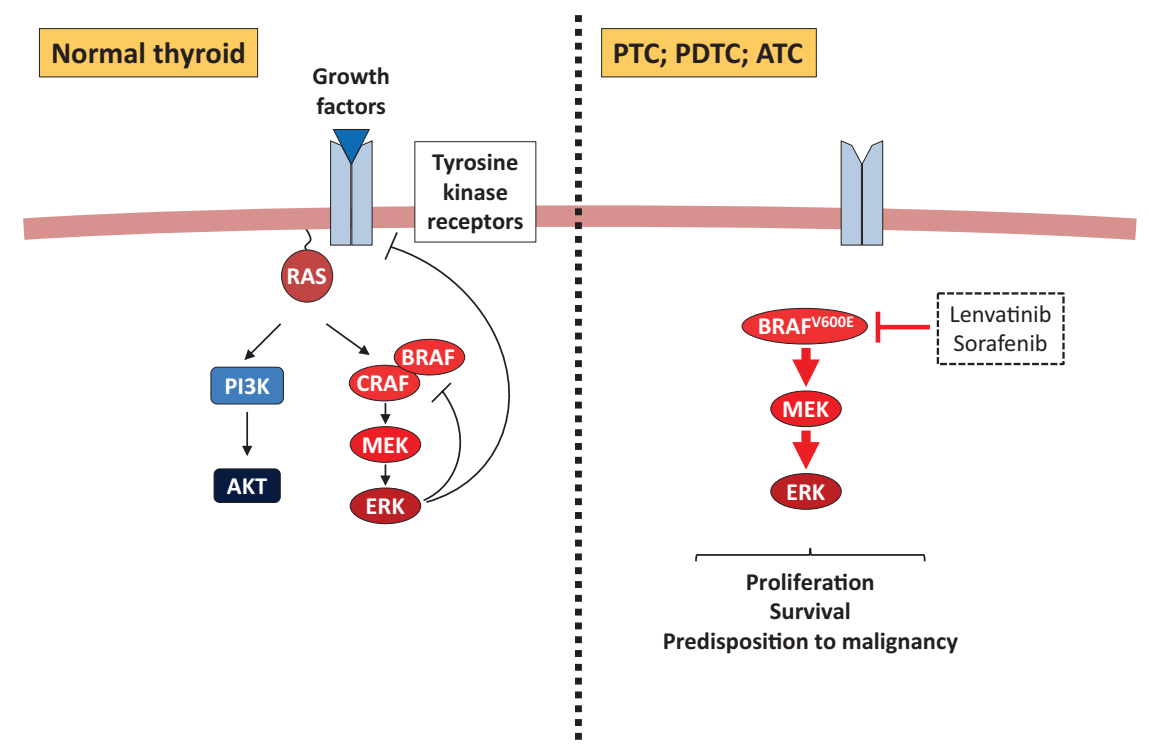

\section{Figure 5}

BRAFV600E mutation in thyroid carcinoma. RAF proteins are one of the main RAS effectors and are subject to negative regulation in normal tissue. Oncogenic BRAFV600E activates the MAPK pathway independently of extracellular stimuli and does not require dimerization. Therefore, there is no negative regulation from ERK to RAF dimerization, inducing a strong activation of the pathway (right). BRAFV600E is associated with CVand TCV-PTC, PDTC and ATC. Small kinase inhibitors against BRAF are shown in dashed boxes. Arrows indicate activation $(\rightarrow)$ and truncated lines inactivation $(-1)$. Red arrows indicate increased flux through the pathway. http://joe.endocrinology-journals.org DOI: $10.1530 / J O E-17-0266$ (c) 2017 Society for Endocrinology Printed in Great Britain 


\section{PI3K pathway}

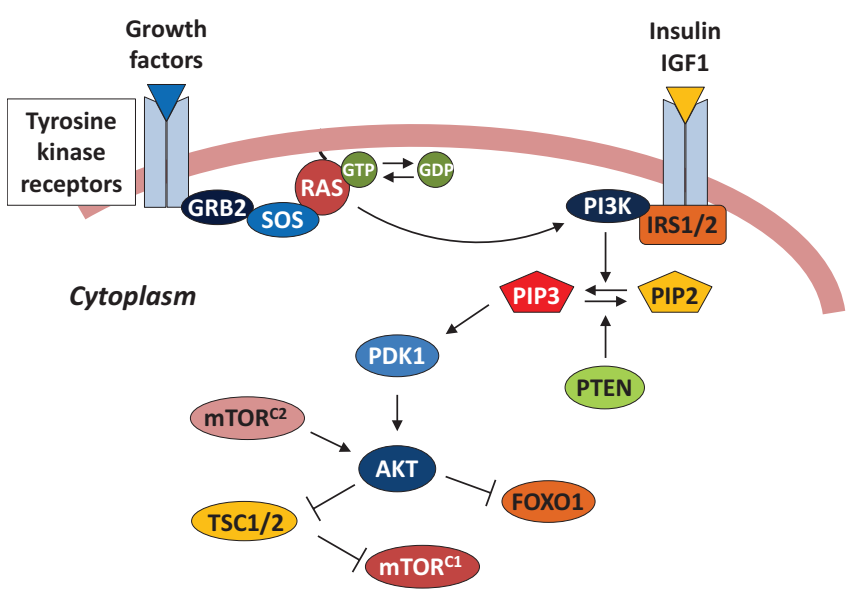

Figure 6

Main components of the PI3K pathway. The PI3K pathway is activated by tyrosine kinase receptors through RAS activation or through recruitment of adaptor proteins that allow PI3K generation of the secondary lipid messenger PIP3. The opposite function is exerted by the lipid phosphatase PTEN. PIP3 promotes AKT activation through phosphorylation by PDK1 and mTORC2. AKT activates downstream effectors such as mTORC1 and FOXO1. Arrows indicate activation $(\rightarrow)$ and truncated lines inactivation $(-)$, the double arrow indicates a reversible state $(\rightleftarrows)$.

consists of a p110 $\gamma$ catalytic subunit that binds to a p101 regulatory subunit and is activated by $\mathrm{G}$ protein-coupled receptors. p110 $\alpha$ and $\beta$ are ubiquitously expressed while p110 1 and $\gamma$ are enriched in leukocytes. In addition, Class 1 PI3Ks have a RAS-binding domain that allows activation by RAS. Mice with mutations in the RAS-binding domain of p110 $\alpha$ die perinatally and the small number that survive show increased resistance to oncogenic RASinduced tumorigenesis, revealing that RAS is essential for both physiological and pathological functions of PI3K (Gupta et al. 2007). Class 3 PI3Ks are formed by a single member Vps34 (vacuolar protein sorting 34) that is involved in the regulation of vesicle trafficking. Class 2 is composed of three monomeric members and their function remains poorly understood.

The Class 1 regulatory subunit is able to bind phosphotyrosine residues on activated membrane receptors, allowing membrane localization of the catalytic subunit that phosphorylates the $3-\mathrm{OH}$ of the phosphatidylinositol ring. This produces the lipid second messenger PIP3, which triggers the activation of downstream effectors with $\mathrm{PH}$ domains such as AKT, PDK1, Tec family of proteins including BTKs (Bruton's tyrosine kinase), the ARF GEFs of the cytohesin family and several other GEFs and GAPs of the RAS family of GTPases.

Among the PI3Ks, Class 1A enzymes have been primarily associated with cancer development. Somatic mutations in PIK3CA, the gene that encodes for the catalytic subunit $\mathrm{p} 110 \alpha$, are frequent in human tumors (Samuels et al. 2004) such as colorectal, gastric, brain or breast tumors. Mutations are especially common in the helical domain, which relieves inhibition by the regulatory subunit, and in the kinase domain, which increases p110 $\alpha$ retention at the plasma membrane (Burke et al. 2012). Mutations in different regulatory subunits can also be found that promote constitutive activation of the catalytic subunit. Conversely, although other members of Class 1A PI3Ks are not found to be mutated, amplifications in human cancer are very common. A role for $\mathrm{p} 110 \beta$ in tumorigenesis is beginning to emerge since this isoform seems to be the main producer of PIP3 in PTEN-deficient tumors (Wee et al. 2008).

In thyroid cancer, somatic mutations of PIK3CA are rare in PTC but relatively common in FTC, PDTC and ATC (Garcia-Rostan et al. 2005). Furthermore, genomic copy gain of PIK3CA has also been frequently observed in cancer. This associates with increased expression of the protein and activation of downstream effectors including AKT, establishing that amplification of the gene has an impact in the signaling output of the pathway (Shayesteh et al. 1999). Amplifications of PIK3CA are also particularly frequent in FTC, PDTC and ATC, but rare in PTC (Wu et al. 2005). Interestingly, PIK3CA mutations and amplifications are usually mutually exclusive, also with mutations in other components of the pathway (Wang et al. 2007), underscoring the importance of this signaling pathway in thyroid tumorigenesis. Moreover, the rate of mutations and amplifications of PIK3CA increases in the most aggressive thyroid tumors, pointing to a role for these genetic events in the progression to undifferentiated forms of thyroid cancer. In addition, PIK3CA mutations can be observed in metastatic cells from PDTC and ATC (Wang et al. 2007). Accordingly, in ATC, PIK3CA mutations were found to be more frequent in the less differentiated region of the tumor. In a recent study using next-generation sequencing of 341 cancer genes from 117 patient-derived PDTCs and ATCs, mutations in different catalytic and regulatory PI3K subunits at a low prevalence were described, indicating that aberrant activation of other PI3K isoforms could have a role in the progression to undifferentiated forms of thyroid cancer (Landa et al. 2016).

\section{PTEN}

PTEN is a dual protein and lipid phosphatase that promotes dephosphorylation of PIP3 on the 3' position

Published by Bioscientifica Ltd. 
of the inositol ring and therefore switches-off PI3K signaling. PTEN is considered a tumor suppressor and its function is frequently disabled in human tumors (Li et al. 1997, Steck et al. 1997). The link between aberrant PI3K signaling and thyroid cancer was first established in patients with Cowden disease, a congenital disorder that causes predisposition to multiple forms of cancer, especially breast, thyroid and endometrium. Eighty percent of the patients with this syndrome present germ-line mutations in PTEN, leading to impaired function or decreased expression of the resultant protein. Interestingly, around $10 \%$ of the patients develop thyroid cancer, mostly FTC, highlighting the importance of PI3K activation for the development of this particular variant of thyroid cancer. Full PTEN inactivation in transgenic mice results in early embryonic lethality, whereas heterozygous Pten knockout mice spontaneously develop thyroid tumors (Di Cristofano et al. 1998). Loss of Pten in the thyroid of transgenic mice results in the early development of diffuse colloid goiter and the later onset of follicular adenomas (Yeager et al. 2007), indicating that PI3K pathway activation is not sufficient to trigger thyroid malignant transformation. Sporadic point mutations or deletions in PTEN in thyroid cancer are found at a low incidence in well-differentiated tumors (Dahia et al. 1997, Halachmi et al. 1998, Hsieh et al. 2000), but are remarkably common in ATC (Landa et al. 2016), suggesting a role for PTEN loss of function in the progression to undifferentiated thyroid cancer. In general, mutations in the PI3K pathway are particularly frequent in undifferentiated thyroid cancer and often co-exist with alterations in the MAPK pathway. A reduction in the expression of the protein is comparatively much more frequent, and hypermethylation of the PTEN promoter has been described to be common in thyroid tumors, indicating that epigenetic mechanisms rather than genetic alterations are responsible for the loss of expression of PTEN in thyroid tumors (Alvarez-Nunez et al. 2006).

\section{Downstream of PI3K: PDK1, AKT and mTOR}

PIP3 generation by PI3K promotes membrane localization of $\mathrm{PH}$ domain-containing proteins such as PDK1 and AKT. Binding of AKT to PIP3 in the membrane induce a conformational change in the structure of the protein that allows the two phosphorylation events required for AKT activation: PDK1 phosphorylates AKT at T308, followed by mTOR (mechanistic target of rapamycin) C2 phosphorylation of S473 (Sarbassov et al. 2005).
The AKT family of serine/threonine kinases is formed by three members encoded by three individual genes. AKT1 and 2 are ubiquitously expressed while AKT3 is largely expressed in brain, heart and kidney. All the isoforms present high homology in their catalytic domain but differ in their regulatory and $\mathrm{PH}$ domains. The three isoforms present common upstream regulators and downstream effectors, and it was initially thought that they perform overlapping functions. However, the different phenotypes of isoform-specific knockout mice indicated that they also fulfill specific tasks (Chen et al. 2001, Cho et al. 2001, Tschopp et al. 2005). AKT is the main mediator of PI3K signaling and is therefore involved in the control of many different processes in the cell, in both physiological and pathological contexts (Toker \& Marmiroli 2014). One of the main AKT effectors responsible for mediating cell growth and control of metabolism is mTOR, a serine/ threonine kinase that exists in two different complexes with different upstream regulation and downstream effectors, different functions and distinct sensitivity to inhibition by rapamycin. As mentioned previously, the mTORC2 or mTOR-Rictor complex is the kinase responsible for AKT S473 phosphorylation while the mTORC1 or mTOR-Raptor complex is activated by AKT by relieving TSC (tuberin sclerosis protein complex) 1 and 2-mediated mTOR inhibition, allowing protein translation and cell growth. This is the best described function for mTOR and it is essential for PI3K pathwayinduced tumorigenesis (Laplante \& Sabatini 2012). Other important AKT effectors include the FOXO (forkhead box O) family of transcription factors, which are negatively regulated by AKT phosphorylation to promote cell growth. In rat thyroid-derived cells, FoxO1 is negatively regulated by thyrotropin and IGF1 and its expression in tumor cells leads to a decrease in their proliferation rate (Zaballos \& Santisteban 2013).

Overall, mutations in PDK1, AKT or mTOR are uncommon, although in specific types of tumors (e.g., breast cancer) a remarkable $20 \%$ incidence of AKT mutations has been reported. In PDTC and ATC, mutations of AKT, mTOR and TSC1/2 at a low prevalence have been recently reported (Landa et al. 2016). AKT amplification has not been fully demonstrated in thyroid carcinomas, although both PDK1 and AKT1/2 amplifications have been reported in FTC and ATC (Liu et al. 2008). However, since AKT and mTOR function as essential mediators of PI3K pathway-driven tumorigenesis, they have consequently emerged as attractive drug targets for the treatment of thyroid cancer. (c) 2017 Society for Endocrinology Printed in Great Britain
Published by Bioscientifica Ltd 
Several drugs that target different components of the PI3K pathway have been tested in preclinical studies using human thyroid tumor-derived cell lines and thyroid cancer animal models. A TR $\beta^{\text {PV/PV }}$ mutant thyroid hormone receptor mouse model that spontaneously develops FTC presented increased PI3K/AKT activation and treatment with a PI3K inhibitor delayed tumor progression and metastatic spread (Furuya et al. 2007). Also, the mTORC1 inhibitor everolimus was found to decrease thyroid tumor growth in a TR $\beta^{\mathrm{PV} / \mathrm{PV}} / \mathrm{Pten}^{+/}-$mouse model, although it had no effect on the development of lung metastases (Guigon et al. 2010). Moreover, a recent phase II clinical trial tested the effects of everolimus for the treatment of locally advanced or metastatic thyroid carcinoma, showing only limited activity (Schneider et al. 2017). Furthermore, the emergence of resistance has been described for mTORC1 inhibitors. It has also been shown that mTORC1 negatively regulates IGF1R signaling and therefore its inhibition increases the activation of the PI3K pathway (O'Reilly et al. 2006).

GDC-0941 is an ATP-competitive inhibitor that has shown activity against Class 1 PI3Ks (Folkes et al. 2008). In an FTC xenograft mouse model, GDC-0941 administration led to a modest reduction in tumor growth and in the number of metastatic lung colonies (Burrows et al. 2011). The AKT inhibitor MK2206 was also shown to reduce growth of human thyroid tumor-derived cell lines with particular sensitivity toward cells harboring mutations that activate the PI3K pathway (Liu et al. 2011).

The main mutations of the PI3K pathway related to thyroid carcinogenesis are represented in Fig. 7.

\section{PAX8/PPAR $\gamma$ rearrangements}

Following RAS point mutations, the PAX8/PPAR gene fusion is the most frequent genetic lesion associated with FTC (30-35\%). It has also been detected in FV-PTC and FTA at lower frequencies (Placzkowski et al. 2008). The PAX8/PPAR $\gamma$ fusion is the result of a chromosomal translocation $(\mathrm{t}(2 ; 3)$ (q13;p25)) that generates a chimeric protein composed of PAX8, minus the C-terminal catalytic domain, fused to fulllength peroxisome proliferator-activated receptor gamma (PPAR $\gamma$ ) (Kroll et al. 2000). Although PPAR $\gamma$ is expressed at low levels in thyroid tissue, an increased expression of the fusion protein driven by the PAX 8 promoter has been detected in thyroid cells (Kroll et al. 2000). A physiological role for PPAR $\gamma$ in thyroid cells has not been described and the mechanisms underlying oncogenic activity of the fusion protein are poorly understood. Some evidence suggests an antagonistic effect of the fusion protein on the activation of PPARy-responsive promoters, and there are also clues that point to a role for PPAR $\gamma$ as a tumor suppressor gene, which could explain the oncogenic activity of the fusion protein (Kroll et al. 2000). Interestingly, PPAR $\gamma$ has been shown to act as a transcription factor to promote PTEN transcription, thereby indirectly activating PI3K signaling (Patel et al. 2001). Consistent with its oncogenic potential, expression of PAX8/PPAR $\gamma$ in human thyroid-derived cells promotes increased growth rate, decreased apoptosis and confers anchorage-independent cell growth (Gregory Powell et al. 2004).

PAX8/PPAR $\gamma$ expression in the thyroid of transgenic mice does not lead to the development of thyroid

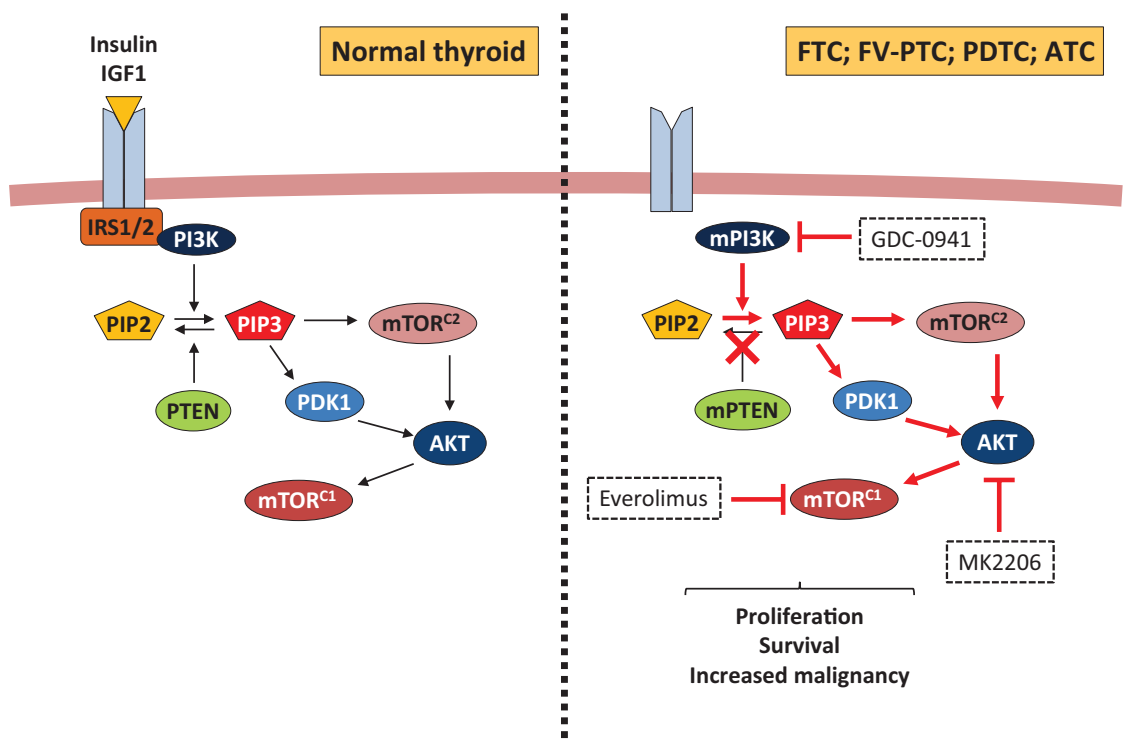

Figure 7
Genetic alterations of the PI3K pathway in thyroid
carcinoma. The binding of insulin or IGF1 to
membrane receptors triggers the recruitment of
adaptor proteins that tether PI3K to the membrane
where it can phosphorylate PIP2, generating the
second messenger PIP3. The opposite process is
performed by PTEN, which dephosphorylates PIP3
to PIP2. PIP3 generation allows phosphorylation of
AKT by PDK1 and mTORC2, leading to full
activation of AKT (left). Mutations in the PI3K
catalytic subunit (mPI3K) or loss of function of
PTEN (mPTEN) lead to activation of the pathway in
the absence of extracellular stimuli (right).
Mutations in this pathway can be found in FTC,
FV-PTC, PDTC and ATC. Small kinase inhibitors
targeting different components of the pathway
are shown in dashed boxes. Arrows indicate
activation $(\rightarrow$ ) and truncated lines inactivation $(-1)$,
the double arrow indicates a reversible state $(\rightleftarrows)$. 
carcinomas, although in a heterozygous PTEN background mice present metastatic thyroid carcinoma (Dobson et al. 2011), indicating that additional genetic events are required for a full transforming phenotype. Interestingly, administration of the PPAR $\gamma$ agonist pioglitazone to these mice resulted in a reduction in tumor size and prevention of metastasis. This finding suggests that pioglitazone could have therapeutic potential in patients with thyroid tumors positive for PAX8/PPAR $\gamma$ fusion protein.

\section{Concluding remarks}

Over the last years, the spectrum of genetic lesions associated with the different types of thyroid carcinomas has been greatly broadened. Knowledge of the signaling pathways activated in both physiological and pathological conditions and the complex intracellular network connecting them has facilitated our understanding of thyroid cancer etiology, which has paved the way for the first trials of a small kinase inhibitor-based therapy. The initial results of this genetic-dependent therapy have been encouraging, but are hampered by the emergence of diverse resistance mechanisms. Thus, future efforts should focus on overcoming drug resistance using combinatorial approaches while maintaining a tolerable toxicity profile. For this to succeed, some crucial aspects such as isoformspecific functions or the crosstalk between the MAPK and PI3K pathways, the principal pathways involved in thyroid tumorigenesis, needs to be clarified.

\section{Declaration of interest}

The authors declare that there is no conflict of interest that could be perceived as prejudicing the impartiality of this review.

\section{Funding}

Supported by the following grants: GCB14142311CRES from the Spanish Foundation against Cancer (F-AECC), SAF2013-44709-R and SAF2016-75531-R from the Ministry of Economy and Competitiveness, RD12/0036/0030 and Ciberonc from the Carlos III Health Institute, (Spain), and the European Regional Development Fund (FEDER).

\section{Acknowledgements}

The authors want to thank the kindness of Dr Inés Martín-Lacave, Department of Cytology and Histology, Medical School, University of Seville (Spain) for providing the Immunohistochemistry images of thyroid tumors. Also we are grateful to Dr Kenneth McCreath for helpful comments on the manuscript and language revision.

\section{References}

Alvarez-Nunez F, Bussaglia E, Mauricio D, Ybarra J, Vilar M, Lerma E, de Leiva A, Matias-Guiu X \& Thyroid Neoplasia Study Group 2006 PTEN promoter methylation in sporadic thyroid carcinomas. Thyroid 16 17-23. (doi:10.1089/thy.2006.16.17)

Amatu A, Sartore-Bianchi A \& Siena S 2016 NTRK gene fusions as novel targets of cancer therapy across multiple tumour types. ESMO Open $\mathbf{1}$ e000023. (doi:10.1136/esmoopen-2015-000023)

Arighi E, Borrello MG \& Sariola H 2005 RET tyrosine kinase signaling in development and cancer. Cytokine and Growth Factor Review 16 441-467. (doi:10.1016/j.cytogfr.2005.05.010)

Bai RY, Ouyang T, Miething C, Morris SW, Peschel C \& Duyster J 2000 Nucleophosmin-anaplastic lymphoma kinase associated with anaplastic large-cell lymphoma activates the phosphatidylinositol 3-kinase/Akt antiapoptotic signaling pathway. Blood 96 4319-4327.

Bos JL 1988 The ras gene family and human carcinogenesis. Mutational Research 195 255-271. (doi:10.1016/0165-1110(88)90004-8)

Bos JL, Rehmann H \& Wittinghofer A 2007 GEFs and GAPs: critical elements in the control of small G proteins. Cell 129 865-877. (doi:10.1016/j.cell.2007.05.018)

Brose MS, Nutting CM, Jarzab B, Elisei R, Siena S, Bastholt L, de la Fouchardiere C, Pacini F, Paschke R, Shong YK, et al. 2014 Sorafenib in radioactive iodine-refractory, locally advanced or metastatic differentiated thyroid cancer: a randomised, double-blind, phase 3 trial. Lancet 384 319-328. (doi:10.1016/S0140-6736(14)60421-9)

Burke JE, Perisic O, Masson GR, Vadas O \& Williams RL 2012 Oncogenic mutations mimic and enhance dynamic events in the natural activation of phosphoinositide 3-kinase p110alpha (PIK3CA). PNAS 109 15259-15264. (doi:10.1073/pnas.1205508109)

Burrows N, Babur M, Resch J, Ridsdale S, Mejin M, Rowling EJ, Brabant G \& Williams KJ 2011 GDC-0941 inhibits metastatic characteristics of thyroid carcinomas by targeting both the phosphoinositide-3 kinase (PI3K) and hypoxia-inducible factor-1alpha (HIF-1alpha) pathways. Journal of Clinical Endocrinology and Metabolism 96 E1934-E1943. (doi:10.1210/jc.2011-1426)

Butti MG, Bongarzone I, Ferraresi G, Mondellini P, Borrello MG \& Pierotti MA 1995 A sequence analysis of the genomic regions involved in the rearrangements between TPM3 and NTRK1 genes producing TRK oncogenes in papillary thyroid carcinomas. Genomics 28 15-24. (doi:10.1006/geno.1995.1100)

Cancer Genome Atlas Research Network 2014 Integrated genomic characterization of papillary thyroid carcinoma. Cell 159 676-690.

Cantley LC 2002 The phosphoinositide 3-kinase pathway. Science 296 1655-1657. (doi:10.1126/science.296.5573.1655)

Carlomagno F, Anaganti S, Guida T, Salvatore G, Troncone G, Wilhelm SM \& Santoro M 2006 BAY 43-9006 inhibition of oncogenic RET mutants. Journal of the National Cancer Institute 98 326-334. (doi:10.1093/jnci/djj069)

Carlomagno F, Vitagliano D, Guida T, Ciardiello F, Tortora G, Vecchio G, Ryan AJ, Fontanini G, Fusco A \& Santoro M 2002 ZD6474, an orally available inhibitor of KDR tyrosine kinase activity, efficiently blocks oncogenic RET kinases. Cancer Research 62 7284-7290.

Castellone MD, Cirafici AM, De Vita G, De Falco V, Malorni L, Tallini G, Fagin JA, Fusco A, Melillo RM \& Santoro M 2003 Ras-mediated apoptosis of PC CL 3 rat thyroid cells induced by RET/PTC oncogenes. Oncogene 22 246-255. (doi:10.1038/sj.onc.1206112)

Ciampi R, Knauf JA, Kerler R, Gandhi M, Zhu Z, Nikiforova MN, Rabes HM, Fagin JA \& Nikiforov YE 2005 Oncogenic AKAP9-BRAF fusion is a novel mechanism of MAPK pathway activation in thyroid cancer. Journal of Clinical Investigation 115 94-101. (doi:10.1172/ JCI23237)

Colin IM, Denef JF, Lengele B, Many MC \& Gerard AC 2013 Recent insights into the cell biology of thyroid angiofollicular units. Endocrine Reviews 34 209-238. (doi:10.1210/er.2012-1015) http://joe.endocrinology-journals.org

DOI: $10.1530 / J O E-17-0266$
() 2017 Society for Endocrinology Printed in Great Britain
Published by Bioscientifica Ltd 
Cote GJ, Grubbs EG \& Hofmann MC 2015 Thyroid C-cell biology and oncogenic transformation. Recent Results in Cancer Research 204 1-39. (doi:10.1007/978-3-319-22542-5_1)

Cox AD, Fesik SW, Kimmelman AC, Luo J \& Der CJ 2014 Drugging the undruggable RAS: mission possible? Nature Reviews Drug Discovery 13 828-851. (doi:10.1038/nrd4389)

Chen WS, Xu PZ, Gottlob K, Chen ML, Sokol K, Shiyanova T, Roninson I Weng W, Suzuki R, Tobe K, et al. 2001 Growth retardation and increased apoptosis in mice with homozygous disruption of the Akt1 gene. Genes and Development 15 2203-2208. (doi:10.1101/gad.913901)

Chiarle R, Simmons WJ, Cai H, Dhall G, Zamo A, Raz R, Karras JG, Levy DE \& Inghirami G 2005 Stat3 is required for ALK-mediated lymphomagenesis and provides a possible therapeutic target. Nature Medicine 11 623-629. (doi:10.1038/nm1249)

Cho H, Mu J, Kim JK, Thorvaldsen JL, Chu Q, Crenshaw EB, 3rd, Kaestner KH, Bartolomei MS, Shulman GI \& Birnbaum MJ 2001 Insulin resistance and a diabetes mellitus-like syndrome in mice lacking the protein kinase Akt2 (PKB beta). Science 292 1728-1731. (doi:10.1126/ science.292.5522.1728)

Choi YL, Soda M, Yamashita Y, Ueno T, Takashima J, Nakajima T, Yatabe Y, Takeuchi K, Hamada T, Haruta H, et al. 2010 EML4-ALK mutations in lung cancer that confer resistance to ALK inhibitors. New England Journal of Medicine 363 1734-1739. (doi:10.1056/NEJMoa1007478)

Chou A, Fraser S, Toon CW, Clarkson A, Sioson L, Farzin M, Cussigh C, Aniss A, O'Neill C, Watson N, et al. 2015 A detailed clinicopathologic study of ALK-translocated papillary thyroid carcinoma. American Journal of Surgical Pathology 39 652-659. (doi:10.1097/ PAS.0000000000000368)

Dahia PL, Marsh DJ, Zheng Z, Zedenius J, Komminoth P, Frisk T, Wallin G, Parsons R, Longy M, Larsson C, et al. 1997 Somatic deletions and mutations in the Cowden disease gene, PTEN, in sporadic thyroid tumors. Cancer Research 57 4710-4713.

Di Cristofano A, Pesce B, Cordon-Cardo C \& Pandolfi PP 1998 Pten is essential for embryonic development and tumour suppression. Nature Genetics 19 348-355. (doi:10.1038/1235)

Dobson ME, Diallo-Krou E, Grachtchouk V, Yu J, Colby LA, Wilkinson JE, Giordano TJ \& Koenig RJ 2011 Pioglitazone induces a proadipogenic antitumor response in mice with PAX8-PPARgamma fusion protein thyroid carcinoma. Endocrinology 152 4455-4465. (doi:10.1210/ en.2011-1178)

Dougherty MK, Muller J, Ritt DA, Zhou M, Zhou XZ, Copeland TD, Conrads TP, Veenstra TD, Lu KP \& Morrison DK 2005 Regulation of Raf-1 by direct feedback phosphorylation. Molecular Cell 17 215-224. (doi:10.1016/j.molcel.2004.11.055)

Durante C, Puxeddu E, Ferretti E, Morisi R, Moretti S, Bruno R, Barbi F, Avenia N, Scipioni A, Verrienti A, et al. 2007 BRAF mutations in papillary thyroid carcinomas inhibit genes involved in iodine metabolism. Journal of Clinical Endocrinology and Metabolism 92 2840-2843. (doi:10.1210/jc.2006-2707)

Elisei R, Romei C, Vorontsova T, Cosci B, Veremeychik V, Kuchinskaya E, Basolo F, Demidchik EP, Miccoli P, Pinchera A, et al. 2001 RET/PTC rearrangements in thyroid nodules: studies in irradiated and not irradiated, malignant and benign thyroid lesions in children and adults. Journal of Clinical Endocrinology and Metabolism 86 3211-3216. (doi:10.1210/jc.86.7.3211)

Esapa CT, Johnson SJ, Kendall-Taylor P, Lennard TW \& Harris PE 1999 Prevalence of Ras mutations in thyroid neoplasia. Clinical Endocrinology 50 529-535. (doi:10.1046/j.1365-2265.1999.00704.x)

Esteban LM, Vicario-Abejon C, Fernandez-Salguero P, FernandezMedarde A, Swaminathan N, Yienger K, Lopez E, Malumbres M, McKay R, Ward JM, et al. 2001 Targeted genomic disruption of H-ras and N-ras, individually or in combination, reveals the dispensability of both loci for mouse growth and development. Molecular and Cellular Biology 21 1444-1452. (doi:10.1128/MCB.21.5.1444-1452.2001)

Folkes AJ, Ahmadi K, Alderton WK, Alix S, Baker SJ, Box G, Chuckowree IS, Clarke PA, Depledge P, Eccles SA, et al. 2008 The identification of
2-(1H-indazol-4-yl)-6-(4-methanesulfonyl-piperazin-1-ylmethyl)-4morpholin-4-yl-t hieno[3,2-d]pyrimidine (GDC-0941) as a potent, selective, orally bioavailable inhibitor of class I PI3 kinase for the treatment of cancer. Journal of Medicinal Chemistry $\mathbf{5 1} 5522-5532$. (doi:10.1021/jm800295d)

Frattini M, Ferrario C, Bressan P, Balestra D, De Cecco L, Mondellini P, Bongarzone I, Collini P, Gariboldi M, Pilotti S, et al. 2004 Alternative mutations of BRAF, RET and NTRK1 are associated with similar but distinct gene expression patterns in papillary thyroid cancer. Oncogene 23 7436-7440. (doi:10.1038/sj.onc.1207980)

Furuya F, Lu C, Willingham MC \& Cheng SY 2007 Inhibition of phosphatidylinositol 3-kinase delays tumor progression and blocks metastatic spread in a mouse model of thyroid cancer. Carcinogenesis 28 2451-2458. (doi:10.1093/carcin/bgm174)

Gandhi M, Dillon LW, Pramanik S, Nikiforov YE \& Wang YH 2010 DNA breaks at fragile sites generate oncogenic RET/PTC rearrangements in human thyroid cells. Oncogene 29 2272-2280. (doi:10.1038/ onc.2009.502)

Garcia-Rostan G, Costa AM, Pereira-Castro I, Salvatore G, Hernandez R, Hermsem MJ, Herrero A, Fusco A, Cameselle-Teijeiro J \& Santoro M 2005 Mutation of the PIK3CA gene in anaplastic thyroid cancer. Cancer Research 65 10199-10207. (doi:10.1158/0008-5472.CAN04-4259)

Godbert Y, Henriques de Figueiredo B, Bonichon F, Chibon F, Hostein I, Perot G, Dupin C, Daubech A, Belleannee G, Gros A, et al. 2015 Remarkable response to crizotinib in woman with anaplastic lymphoma kinase-rearranged anaplastic thyroid carcinoma. Journal of Clinical Oncology 33 e84-e87. (doi:10.1200/ JCO.2013.49.6596)

Greco A, Mariani C, Miranda C, Lupas A, Pagliardini S, Pomati M \& Pierotti MA 1995 The DNA rearrangement that generates the TRK-T3 oncogene involves a novel gene on chromosome 3 whose product has a potential coiled-coil domain. Molecular and Cellular Biology 15 6118-6127. (doi:10.1128/MCB.15.11.6118)

Greco A, Pierotti MA, Bongarzone I, Pagliardini S, Lanzi C \& Della Porta G 1992 TRK-T1 is a novel oncogene formed by the fusion of TPR and TRK genes in human papillary thyroid carcinomas. Oncogene 7 237-242.

Gregory Powell J, Wang X, Allard BL, Sahin M, Wang XL, Hay ID, Hiddinga HJ, Deshpande SS, Kroll TG, Grebe SK, et al. 2004 The PAX8/PPARgamma fusion oncoprotein transforms immortalized human thyrocytes through a mechanism probably involving wildtype PPARgamma inhibition. Oncogene 23 3634-3641. (doi:10.1038/ sj.onc.1207399)

Grieco M, Santoro M, Berlingieri MT, Melillo RM, Donghi R, Bongarzone I, Pierotti MA, Della Porta G, Fusco A \& Vecchio G 1990 PTC is a novel rearranged form of the ret proto-oncogene and is frequently detected in vivo in human thyroid papillary carcinomas. Cell 60 557-563. (doi:10.1016/0092-8674(90)90659-3)

Griffin CA, Hawkins AL, Dvorak C, Henkle C, Ellingham T \& Perlman EJ 1999 Recurrent involvement of 2p23 in inflammatory myofibroblastic tumors. Cancer Research 59 2776-2780.

Guigon CJ, Fozzatti L, Lu C, Willingham MC \& Cheng SY 2010 Inhibition of mTORC1 signaling reduces tumor growth but does not prevent cancer progression in a mouse model of thyroid cancer. Carcinogenesis 31 1284-1291. (doi:10.1093/carcin/bgq059)

Gupta S, Ramjaun AR, Haiko P, Wang Y, Warne PH, Nicke B, Nye E, Stamp G, Alitalo K \& Downward J 2007 Binding of ras to phosphoinositide 3-kinase p110alpha is required for ras-driven tumorigenesis in mice. Cell 129 957-968. (doi:10.1016/j. cell.2007.03.051)

Haigis KM, Kendall KR, Wang Y, Cheung A, Haigis MC, Glickman JN, Niwa-Kawakita M, Sweet-Cordero A, Sebolt-Leopold J, Shannon KM, et al. 2008 Differential effects of oncogenic K-Ras and N-Ras on proliferation, differentiation and tumor progression in the colon. Nature Genetics 40 600-608. (doi:10.1038/ng.115) 
Halachmi N, Halachmi S, Evron E, Cairns P, Okami K, Saji M, Westra WH, Zeiger MA, Jen J \& Sidransky D 1998 Somatic mutations of the PTEN tumor suppressor gene in sporadic follicular thyroid tumors. Genes, Chromosomes and Cancer 23 239-243. (doi:10.1002/(SICI)10982264(199811)23:3<239::AID-GCC5>3.0.CO;2-2)

Hamatani K, Mukai M, Takahashi K, Hayashi Y, Nakachi K \& Kusunoki Y 2012 Rearranged anaplastic lymphoma kinase (ALK) gene in adultonset papillary thyroid cancer amongst atomic bomb survivors. Thyroid 22 1153-1159. (doi:10.1089/thy.2011.0511)

Hay ID, Thompson GB, Grant CS, Bergstralh EJ, Dvorak CE, Gorman CA, Maurer MS, McIver B, Mullan BP, Oberg AL, et al. 2002 Papillary thyroid carcinoma managed at the Mayo Clinic during six decades (1940-1999): temporal trends in initial therapy and long-term outcome in 2444 consecutively treated patients. World Journal of Surgery 26 879-885. (doi:10.1007/s00268-002-6612-1)

Ho AL, Grewal RK, Leboeuf R, Sherman EJ, Pfister DG, Deandreis D, Pentlow KS, Zanzonico PB, Haque S, Gavane S, et al. 2013 Selumetinibenhanced radioiodine uptake in advanced thyroid cancer. New England Journal of Medicine 368 623-632. (doi:10.1056/NEJMoa1209288)

Horn S, Figl A, Rachakonda PS, Fischer C, Sucker A, Gast A, Kadel S, Moll I, Nagore E, Hemminki K, et al. 2013 TERT promoter mutations in familial and sporadic melanoma. Science 339 959-961. (doi:10.1126/ science.1230062)

Hou P, Liu D \& Xing M 2011 Genome-wide alterations in gene methylation by the BRAF V600E mutation in papillary thyroid cancer cells. Endocrine-Related Cancer 18 687-697. (doi:10.1530/ERC-11-0212)

Hsieh MC, Lin SF, Shin SJ, Liu TC, Chang JG \& Lee JP 2000 Mutation analysis of PTEN/MMAC 1 in sporadic thyroid tumors. Kaohsiung Journal of Medical Sciences 16 9-12.

Hu S, Liu D, Tufano RP, Carson KA, Rosenbaum E, Cohen Y, Holt EH, Kiseljak-Vassiliades K, Rhoden KJ, Tolaney S, et al. 2006 Association of aberrant methylation of tumor suppressor genes with tumor aggressiveness and BRAF mutation in papillary thyroid cancer. International Journal of Cancer 119 2322-2329. (doi:10.1002/ijc.22110)

Huang FW, Hodis E, Xu MJ, Kryukov GV, Chin L \& Garraway LA 2013 Highly recurrent TERT promoter mutations in human melanoma. Science 339 957-959. (doi:10.1126/science.1229259)

Huleihel M, Goldsborough M, Cleveland J, Gunnell M, Bonner T \& Rapp UR 1986 Characterization of murine A-raf, a new oncogene related to the v-raf oncogene. Molecular and Cellular Biology 6 2655-2662. (doi:10.1128/MCB.6.7.2655)

Ikawa S, Fukui M, Ueyama Y, Tamaoki N, Yamamoto T \& Toyoshima K 1988 B-raf, a new member of the raf family, is activated by DNA rearrangement. Molecular and Cellular Biology 8 2651-2654. (doi:10.1128/MCB.8.6.2651)

Ishizaka Y, Kobayashi S, Ushijima T, Hirohashi S, Sugimura T \& Nagao M 1991 Detection of retTPC/PTC transcripts in thyroid adenomas and adenomatous goiter by an RT-PCR method. Oncogene 6 1667-1672.

Iwahara T, Fujimoto J, Wen D, Cupples R, Bucay N, Arakawa T, Mori S, Ratzkin B \& Yamamoto T 1997 Molecular characterization of ALK, a receptor tyrosine kinase expressed specifically in the nervous system. Oncogene 14 439-449. (doi:10.1038/sj.onc.1200849)

Jhiang SM, Sagartz JE, Tong Q, Parker-Thornburg J, Capen CC, Cho JY, Xing S \& Ledent C 1996 Targeted expression of the ret/PTC1 oncogene induces papillary thyroid carcinomas. Endocrinology 137 375-378. (doi:10.1210/endo.137.1.8536638)

Kaplan DR \& Miller FD 2000 Neurotrophin signal transduction in the nervous system. Current Opinion in Neurobiology $10381-391$. (doi:10.1016/S0959-4388(00)00092-1)

Kelly LM, Barila G, Liu P, Evdokimova VN, Trivedi S, Panebianco F, Gandhi M, Carty SE, Hodak SP, Luo J, et al. 2014 Identification of the transforming STRN-ALK fusion as a potential therapeutic target in the aggressive forms of thyroid cancer. PNAS $1114233-4238$. (doi:10.1073/pnas.1321937111)

Kimura ET, Nikiforova MN, Zhu Z, Knauf JA, Nikiforov YE \& Fagin JA 2003 High prevalence of BRAF mutations in thyroid cancer: genetic evidence for constitutive activation of the RET/PTC-RAS-BRAF signaling pathway in papillary thyroid carcinoma. Cancer Research 63 1454-1457.

Knauf JA, Kuroda H, Basu S \& Fagin JA 2003 RET/PTC-induced dedifferentiation of thyroid cells is mediated through Y1062 signaling through SHC-RAS-MAP kinase. Oncogene 22 4406-4412. (doi:10.1038/ sj.onc.1206602)

Knauf JA, Ma X, Smith EP, Zhang L, Mitsutake N, Liao XH, Refetoff S, Nikiforov YE \& Fagin JA 2005 Targeted expression of BRAFV600E in thyroid cells of transgenic mice results in papillary thyroid cancers that undergo dedifferentiation. Cancer Research 65 4238-4245. (doi:10.1158/0008-5472.CAN-05-0047)

Koera K, Nakamura K, Nakao K, Miyoshi J, Toyoshima K, Hatta T, Otani H, Aiba A \& Katsuki M 1997 K-ras is essential for the development of the mouse embryo. Oncogene 15 1151-1159. (doi:10.1038/sj.onc.1201284)

Krishna M \& Narang H 2008 The complexity of mitogen-activated protein kinases (MAPKs) made simple. Cellular and Molecular Life Sciences 65 3525-3544. (doi:10.1007/s00018-008-8170-7)

Kroll TG, Sarraf P, Pecciarini L, Chen CJ, Mueller E, Spiegelman BM \& Fletcher JA 2000 PAX8-PPARgamma1 fusion oncogene in human thyroid carcinoma (corrected). Science 289 1357-1360. (doi:10.1126/ science.289.5483.1357)

Landa I, Ganly I, Chan TA, Mitsutake N, Matsuse M, Ibrahimpasic T, Ghossein RA \& Fagin JA 2013 Frequent somatic TERT promoter mutations in thyroid cancer: higher prevalence in advanced forms of the disease. Journal of Clinical Endocrinology and Metabolism 98 E1562-E1566. (doi:10.1210/jc.2013-2383)

Landa I, Ibrahimpasic T, Boucai L, Sinha R, Knauf JA, Shah RH, Dogan S, Ricarte-Filho JC, Krishnamoorthy GP, Xu B, et al. 2016 Genomic and transcriptomic hallmarks of poorly differentiated and anaplastic thyroid cancers. Journal of Clinical Investigation 126 1052-1066. (doi:10.1172/JCI85271)

Laplante M \& Sabatini DM 2012 mTOR signaling in growth control and disease. Cell 149 274-293. (doi:10.1016/j.cell.2012.03.017)

Lavoie H \& Therrien M 2015 Regulation of RAF protein kinases in ERK signalling. Nature Reviews Molecular Cell Biology 16 281-298. (doi:10.1038/nrm3979)

Leeman-Neill RJ, Kelly LM, Liu P, Brenner AV, Little MP, Bogdanova TI, Evdokimova VN, Hatch M, Zurnadzy LY, Nikiforova MN, et al. 2014 ETV6-NTRK3 is a common chromosomal rearrangement in radiationassociated thyroid cancer. Cancer 120 799-807. (doi:10.1002/ cncr.28484)

Li J, Yen C, Liaw D, Podsypanina K, Bose S, Wang SI, Puc J, Miliaresis C, Rodgers L, McCombie R, et al. 1997 PTEN, a putative protein tyrosine phosphatase gene mutated in human brain, breast, and prostate cancer. Science 275 1943-1947. (doi:10.1126/science.275.5308.1943)

Lim H, Devesa SS, Sosa JA, Check D \& Kitahara CM 2017 Trends in thyroid cancer incidence and mortality in the United States, 1974 2013. JAMA 317 1338-1348. (doi:10.1001/jama.2017.2719)

Liu R, Liu D, Trink E, Bojdani E, Ning G \& Xing M 2011 The Akt-specific inhibitor MK2206 selectively inhibits thyroid cancer cells harboring mutations that can activate the PI3K/Akt pathway. Journal of Clinical Endocrinology and Metabolism 96 E577-E585. (doi:10.1210/jc.2010-2644)

Liu X, Bishop J, Shan Y, Pai S, Liu D, Murugan AK, Sun H, El-Naggar AK \& Xing M 2013 Highly prevalent TERT promoter mutations in aggressive thyroid cancers. Endocrine-Related Cancer 20 603-610. (doi:10.1530/ERC-13-0210)

Liu Z, Hou P, Ji M, Guan H, Studeman K, Jensen K, Vasko V, El-Naggar AK \& Xing M 2008 Highly prevalent genetic alterations in receptor tyrosine kinases and phosphatidylinositol 3-kinase/akt and mitogenactivated protein kinase pathways in anaplastic and follicular thyroid cancers. Journal of Clinical Endocrinology and Metabolism 93 3106-3116. (doi:10.1210/jc.2008-0273)

Melo M, Gaspar da Rocha A, Batista R, Vinagre J, Martins MJ, Costa G, Ribeiro C, Carrilho F, Leite V, Lobo C, et al. 2017 TERT, BRAF, and 
NRAS in primary thyroid cancer and metastatic disease. Journal of Clinical Endocrinology and Metabolism 102 1898-1907. (doi:10.1210/ jc.2016-2785)

Mitsutake N, Knauf JA, Mitsutake S, Mesa C Jr, Zhang L \& Fagin JA 2005 Conditional BRAFV600E expression induces DNA synthesis, apoptosis, dedifferentiation, and chromosomal instability in thyroid PCCL3 cells. Cancer Research 65 2465-2473. (doi:10.1158/0008-5472. CAN-04-3314)

Morris SW, Kirstein MN, Valentine MB, Dittmer KG, Shapiro DN, Saltman DL \& Look AT 1994 Fusion of a kinase gene, ALK, to a nucleolar protein gene, NPM, in non-Hodgkin's lymphoma. Science $\mathbf{2 6 3}$ 1281-1284. (doi:10.1126/science.8122112)

Morris SW, Naeve C, Mathew P, James PL, Kirstein MN, Cui X \& Witte DP 1997 ALK, the chromosome 2 gene locus altered by the $t(2 ; 5)$ in nonHodgkin's lymphoma, encodes a novel neural receptor tyrosine kinase that is highly related to leukocyte tyrosine kinase (LTK). Oncogene 14 2175-2188. (doi:10.1038/sj.onc.1201062)

Motegi A, Fujimoto J, Kotani M, Sakuraba H \& Yamamoto T 2004 ALK receptor tyrosine kinase promotes cell growth and neurite outgrowth. Journal of Cell Science 117 3319-3329. (doi:10.1242/jcs.01183)

Mulligan LM 2014 RET revisited: expanding the oncogenic portfolio. Nature Reviews Cancer 14 173-186. (doi:10.1038/nrc3680)

Murugan AK \& Xing M 2011 Anaplastic thyroid cancers harbor novel oncogenic mutations of the ALK gene. Cancer Research 71 4403-4411. (doi:10.1158/0008-5472.CAN-10-4041)

Nagarajah J, Le M, Knauf JA, Ferrandino G, Montero-Conde C, Pillarsetty N, Bolaender A, Irwin C, Krishnamoorthy GP, Saqcena M, et al. 2016 Sustained ERK inhibition maximizes responses of BrafV600E thyroid cancers to radioiodine. Journal of Clinical Investigation $\mathbf{1 2 6}$ 4119-4124. (doi:10.1172/JCI89067)

Nakamura TM, Morin GB, Chapman KB, Weinrich SL, Andrews WH, Lingner J, Harley CB \& Cech TR 1997 Telomerase catalytic subunit homologs from fission yeast and human. Science 277 955-959. (doi:10.1126/science.277.5328.955)

Nikiforov YE 2002 RET/PTC rearrangement in thyroid tumors. Endocrine Pathology 13 3-16. (doi:10.1385/EP:13:1:03)

Nikiforov YE, Rowland JM, Bove KE, Monforte-Munoz H \& Fagin JA 1997 Distinct pattern of ret oncogene rearrangements in morphological variants of radiation-induced and sporadic thyroid papillary carcinomas in children. Cancer Research 57 1690-1694.

Nikiforova MN, Kimura ET, Gandhi M, Biddinger PW, Knauf JA, Basolo F, Zhu Z, Giannini R, Salvatore G, Fusco A, et al. 2003 BRAF mutations in thyroid tumors are restricted to papillary carcinomas and anaplastic or poorly differentiated carcinomas arising from papillary carcinomas. Journal of Clinical Endocrinology and Metabolism $\mathbf{8 8}$ 5399-5404. (doi:10.1210/jc.2003-030838)

Nikiforova MN, Stringer JR, Blough R, Medvedovic M, Fagin JA \& Nikiforov YE 2000 Proximity of chromosomal loci that participate in radiation-induced rearrangements in human cells. Science $\mathbf{2 9 0}$ 138-141. (doi:10.1126/science.290.5489.138)

O'Reilly KE, Rojo F, She QB, Solit D, Mills GB, Smith D, Lane H, Hofmann F, Hicklin DJ, Ludwig DL, et al. 2006 mTOR inhibition induces upstream receptor tyrosine kinase signaling and activates Akt. Cancer Research 66 1500-1508.

Okamoto K, Kodama K, Takase K, Sugi NH, Yamamoto Y, Iwata M \& Tsuruoka A 2013 Antitumor activities of the targeted multi-tyrosine kinase inhibitor lenvatinib (E7080) against RET gene fusiondriven tumor models. Cancer Letters 340 97-103. (doi:10.1016/j. canlet.2013.07.007)

Ou SH, Klempner SJ, Greenbowe JR, Azada M, Schrock AB, Ali SM, Ross JS, Stephens PJ \& Miller VA 2014 Identification of a novel HIP1-ALK fusion variant in Non-Small-Cell Lung Cancer (NSCLC) and discovery of ALK I1171 (I1171N/S) mutations in two ALK-rearranged NSCLC patients with resistance to Alectinib. Journal of Thoracic Oncology 9 1821-1825. (doi:10.1097/JTO.0000000000000368)
Patel L, Pass I, Coxon P, Downes CP, Smith SA \& Macphee CH 2001 Tumor suppressor and anti-inflammatory actions of PPARgamma agonists are mediated via upregulation of PTEN. Current Biology 11 764-768. (doi:10.1016/S0960-9822(01)00225-1)

Placzkowski KA, Reddi HV, Grebe SK, Eberhardt NL \& McIver B 2008 The role of the PAX8/PPARgamma fusion oncogene in thyroid cancer. PPAR Research 2008672829.

Powell DJ Jr, Russell J, Nibu K, Li G, Rhee E, Liao M, Goldstein M, Keane WM, Santoro M, Fusco A, et al. 1998 The RET/PTC3 oncogene: metastatic solid-type papillary carcinomas in murine thyroids. Cancer Research 58 5523-5528.

Prior IA \& Hancock JF 2012 Ras trafficking, localization and compartmentalized signalling. Seminars in Cell and Developmental Biology 23 145-153. (doi:10.1016/j.semcdb.2011.09.002)

Prior IA, Lewis PD \& Mattos C 2012 A comprehensive survey of Ras mutations in cancer. Cancer Research 72 2457-2467. (doi:10.1158/0008-5472.CAN-11-2612)

Rapp UR, Goldsborough MD, Mark GE, Bonner TI, Groffen J, Reynolds FH Jr \& Stephenson JR 1983 Structure and biological activity of v-raf, a unique oncogene transduced by a retrovirus. PNAS $\mathbf{8 0} 4218-4222$. (doi:10.1073/pnas.80.14.4218)

Riesco-Eizaguirre G, Gutierrez-Martinez P, Garcia-Cabezas MA, Nistal M \& Santisteban P 2006 The oncogene BRAF V600E is associated with a high risk of recurrence and less differentiated papillary thyroid carcinoma due to the impairment of $\mathrm{Na}+/ \mathrm{I}-$ targeting to the membrane. Endocrine-Related Cancer 13 257-269. (doi:10.1677/ erc.1.01119)

Ritt DA, Monson DM, Specht SI \& Morrison DK 2010 Impact of feedback phosphorylation and Raf heterodimerization on normal and mutant B-Raf signaling. Molecular and Cellular Biology 30 806-819. (doi:10.1128/MCB.00569-09)

Roccato E, Bressan P, Sabatella G, Rumio C, Vizzotto L, Pierotti MA \& Greco A 2005 Proximity of TPR and NTRK1 rearranging loci in human thyrocytes. Cancer Research 65 2572-2576. (doi:10.1158/0008-5472. CAN-04-4294)

Romei C, Ciampi R, Faviana P, Agate L, Molinaro E, Bottici V, Basolo F, Miccoli P, Pacini F, Pinchera A, et al. 2008 BRAFV600E mutation, but not RET/PTC rearrangements, is correlated with a lower expression of both thyroperoxidase and sodium iodide symporter genes in papillary thyroid cancer. Endocrine-Related Cancer 15 511-520. (doi:10.1677/ ERC-07-0130)

Russell JP, Powell DJ, Cunnane M, Greco A, Portella G, Santoro M, Fusco A \& Rothstein JL 2000 The TRK-T1 fusion protein induces neoplastic transformation of thyroid epithelium. Oncogene 195729 5735. (doi:10.1038/sj.onc.1203922)

Saavedra HI, Knauf JA, Shirokawa JM, Wang J, Ouyang B, Elisei R, Stambrook PJ \& Fagin JA 2000 The RAS oncogene induces genomic instability in thyroid PCCL3 cells via the MAPK pathway. Oncogene 19 3948-3954. (doi:10.1038/sj.onc.1203723)

Samuels Y, Wang Z, Bardelli A, Silliman N, Ptak J, Szabo S, Yan H, Gazdar A, Powell SM, Riggins GJ, et al. 2004 High frequency of mutations of the PIK3CA gene in human cancers. Science $\mathbf{3 0 4} 554$. (doi:10.1126/science.1096502)

Santarpia L, Myers JN, Sherman SI, Trimarchi F, Clayman GL \& El-Naggar AK 2010 Genetic alterations in the RAS/RAF/mitogen-activated protein kinase and phosphatidylinositol 3-kinase/Akt signaling pathways in the follicular variant of papillary thyroid carcinoma. Cancer 116 2974-2983. (doi:10.1002/cncr.25061)

Santoro M, Chiappetta G, Cerrato A, Salvatore D, Zhang L, Manzo G, Picone A, Portella G, Santelli G, Vecchio G, et al. 1996 Development of thyroid papillary carcinomas secondary to tissue-specific expression of the RET/PTC1 oncogene in transgenic mice. Oncogene 12 1821-1826.

Santoro M, Dathan NA, Berlingieri MT, Bongarzone I, Paulin C, Grieco M, Pierotti MA, Vecchio G \& Fusco A 1994 Molecular characterization of http://joe.endocrinology-journals.org

DOI: $10.1530 / J O E-17-0266$
(C) 2017 Society for Endocrinology Printed in Great Britain
Published by Bioscientifica Ltd 
RET/PTC3; a novel rearranged version of the RETproto-oncogene in a human thyroid papillary carcinoma. Oncogene 9 509-516.

Santoro M, Melillo RM, Grieco M, Berlingieri MT, Vecchio G \& Fusco A 1993 The TRK and RET tyrosine kinase oncogenes cooperate with ras in the neoplastic transformation of a rat thyroid epithelial cell line. Cell Growth and Differentiation 4 77-84.

Sapio MR, Guerra A, Marotta V, Campanile E, Formisano R, Deandrea M, Motta M, Limone PP, Fenzi G, Rossi G, et al. 2011 High growth rate of benign thyroid nodules bearing RET/PTC rearrangements. Journal of Clinical Endocrinology and Metabolism 96 E916-E919. (doi:10.1210/ jc.2010-1599)

Sarbassov DD, Guertin DA, Ali SM \& Sabatini DM 2005 Phosphorylation and regulation of Akt/PKB by the rictor-mTOR complex. Science $\mathbf{3 0 7}$ 1098-1101. (doi:10.1126/science.1106148)

Sartore-Bianchi A, Ardini E, Bosotti R, Amatu A, Valtorta E, Somaschini A, Raddrizzani L, Palmeri L, Banfi P, Bonazzina E, et al. 2016 Sensitivity to entrectinib associated with a novel LMNA-NTRK1 gene fusion in metastatic colorectal cancer. Journal of the National Cancer Institute $\mathbf{1 0 8 .}$

Schlumberger M, Tahara M, Wirth LJ, Robinson B, Brose MS, Elisei R, Habra MA, Newbold K, Shah MH, Hoff AO, et al. 2015 Lenvatinib versus placebo in radioiodine-refractory thyroid cancer. New England Journal of Medicine 372 621-630. (doi:10.1056/NEJMoa1406470)

Schneider TC, de Wit D, Links TP, van Erp NP, van der Hoeven JJ, Gelderblom H, Roozen IC, Bos M, Corver WE, van Wezel T, et al. 2017 Everolimus in patients with advanced follicular-derived thyroid cancer: results of a phase II clinical trial. Journal of Clinical Endocrinology and Metabolism 102 698-707.

Shaul YD \& Seger R 2007 The MEK/ERK cascade: from signaling specificity to diverse functions. Biochimica et Biophysica Acta 1773 1213-1226. (doi:10.1016/j.bbamcr.2006.10.005)

Shayesteh L, Lu Y, Kuo WL, Baldocchi R, Godfrey T, Collins C, Pinkel D, Powell B, Mills GB \& Gray JW 1999 PIK3CA is implicated as an oncogene in ovarian cancer. Nature Genetics 21 99-102. (doi:10.1038/5042)

Shi X, Liu R, Qu S, Zhu G, Bishop J, Liu X, Sun H, Shan Z, Wang E, Luo Y, et al. 2015 Association of TERT promoter mutation 1,295,228 C>T with BRAF V600E mutation, older patient age, and distant metastasis in anaplastic thyroid cancer. Journal of Clinical Endocrinology and Metabolism 100 E632-E637. (doi:10.1210/jc.2014-3606)

Soares P, Trovisco V, Rocha AS, Lima J, Castro P, Preto A, Maximo V, Botelho T, Seruca R \& Sobrinho-Simoes M 2003 BRAF mutations and RET/PTC rearrangements are alternative events in the etiopathogenesis of PTC. Oncogene 22 4578-4580. (doi:10.1038/ sj.onc.1206706)

Soda M, Choi YL, Enomoto M, Takada S, Yamashita Y, Ishikawa S, Fujiwara S, Watanabe H, Kurashina K, Hatanaka H, et al. 2007 Identification of the transforming EML4-ALK fusion gene in non-small-cell lung cancer. Nature 448 561-566. (doi:10.1038/ nature05945)

Souttou B, Carvalho NB, Raulais D \& Vigny M 2001 Activation of anaplastic lymphoma kinase receptor tyrosine kinase induces neuronal differentiation through the mitogen-activated protein kinase pathway. Journal of Biological Chemistry 276 9526-9531. (doi:10.1074/jbc.M007333200)

Steck PA, Pershouse MA, Jasser SA, Yung WK, Lin H, Ligon AH, Langford LA, Baumgard ML, Hattier T, Davis T, et al. 1997 Identification of a candidate tumour suppressor gene, MMAC1, at chromosome 10q23.3 that is mutated in multiple advanced cancers. Nature Genetics $\mathbf{1 5}$ 356-362. (doi:10.1038/ng0497-356)

Suarez HG, Du Villard JA, Caillou B, Schlumberger M, Tubiana M, Parmentier C \& Monier R 1988 Detection of activated ras oncogenes in human thyroid carcinomas. Oncogene 2 403-406.

Toker A \& Marmiroli S 2014 Signaling specificity in the Akt pathway in biology and disease. Advances in Biological Regulation 55 28-38. (doi:10.1016/j.jbior.2014.04.001)
Trapasso F, Iuliano R, Chiefari E, Arturi F, Stella A, Filetti S, Fusco A \& Russo D 1999 Iodide symporter gene expression in normal and transformed rat thyroid cells. European Journal of Endocrinolog 140 447-451. (doi:10.1530/eje.0.1400447)

Trovisco V, Vieira de Castro I, Soares P, Maximo V, Silva P, Magalhaes J, Abrosimov A, Guiu XM \& Sobrinho-Simoes M 2004 BRAF mutations are associated with some histological types of papillary thyroid carcinoma. Journal of Pathology 202 247-251. (doi:10.1002/path.1511)

Tschopp O, Yang ZZ, Brodbeck D, Dummler BA, Hemmings-Mieszczak M, Watanabe T, Michaelis T, Frahm J \& Hemmings BA 2005 Essential role of protein kinase B gamma (PKB gamma/Akt3) in postnatal brain development but not in glucose homeostasis. Development 132 2943-2954. (doi:10.1242/dev.01864)

Umanoff H, Edelmann W, Pellicer A \& Kucherlapati R 1995 The murine N-ras gene is not essential for growth and development. PNAS 92 1709-1713. (doi:10.1073/pnas.92.5.1709)

Vanhaesebroeck B, Guillermet-Guibert J, Graupera M \& Bilanges B 2010 The emerging mechanisms of isoform-specific PI3K signalling. Nature Reviews Molecular Cell Biology 11 329-341. (doi:10.1038/ nrm2882)

Vasko V, Ferrand M, Di Cristofaro J, Carayon P, Henry JF \& de Micco C 2003 Specific pattern of RAS oncogene mutations in follicular thyroid tumors. Journal of Clinical Endocrinology and Metabolism 88 2745-2752. (doi:10.1210/jc.2002-021186)

Vernersson E, Khoo NK, Henriksson ML, Roos G, Palmer RH \& Hallberg B 2006 Characterization of the expression of the ALK receptor tyrosine kinase in mice. Gene Expression Patterns 6 448-461. (doi:10.1016/j. modgep.2005.11.006)

Viglietto G, Chiappetta G, Martinez-Tello FJ, Fukunaga FH, Tallini G, Rigopoulou D, Visconti R, Mastro A, Santoro M \& Fusco A 1995 RET/ PTC oncogene activation is an early event in thyroid carcinogenesis. Oncogene 11 1207-1210.

Vinagre J, Almeida A, Populo H, Batista R, Lyra J, Pinto V, Coelho R, Celestino R, Prazeres H, Lima L, et al. 2013 Frequency of TERT promoter mutations in human cancers. Nature Communication 42185.

Vitagliano D, Portella G, Troncone G, Francione A, Rossi C, Bruno A, Giorgini A, Coluzzi S, Nappi TC, Rothstein JL, et al. 2006 Thyroid targeting of the $\mathrm{N}$-ras(Gln61Lys) oncogene in transgenic mice results in follicular tumors that progress to poorly differentiated carcinomas. Oncogene 25 5467-5474. (doi:10.1038/sj.onc.1209527)

Walsh AB \& Bar-Sagi D 2001 Differential activation of the Rac pathway by Ha-Ras and K-Ras. Journal of Biological Chemistry 276 15609-15615. (doi:10.1074/jbc.M010573200)

Wang J, Knauf JA, Basu S, Puxeddu E, Kuroda H, Santoro M, Fusco A \& Fagin JA 2003 Conditional expression of RET/PTC induces a weak oncogenic drive in thyroid PCCL3 cells and inhibits thyrotropin action at multiple levels. Molecular Endocrinology 17 1425-1436. (doi:10.1210/me.2003-0041)

Wang Y, Hou P, Yu H, Wang W, Ji M, Zhao S, Yan S, Sun X, Liu D, Shi B, et al. 2007 High prevalence and mutual exclusivity of genetic alterations in the phosphatidylinositol-3-kinase/akt pathway in thyroid tumors. Journal of Clinical Endocrinology and Metabolism 92 2387-2390. (doi:10.1210/jc.2006-2019)

Wee S, Wiederschain D, Maira SM, Loo A, Miller C, deBeaumont R, Stegmeier F, Yao YM \& Lengauer C 2008 PTEN-deficient cancers depend on PIK3CB. PNAS 105 13057-13062. (doi:10.1073/ pnas.0802655105)

Wirtschafter A, Schmidt R, Rosen D, Kundu N, Santoro M, Fusco A, Multhaupt H, Atkins JP, Rosen MR, Keane WM, et al. 1997 Expression of the RET/PTC fusion gene as a marker for papillary carcinoma in Hashimoto's thyroiditis. Laryngoscope 107 95-100. (doi:10.1097/00005537-199701000-00019)

Wiseman SM, Loree TR, Hicks WL, Jr., Rigual NR, Winston JS, Tan D, Anderson GR \& Stoler DL 2003a Anaplastic thyroid cancer evolved from papillary carcinoma: demonstration of anaplastic transformation by means of the inter-simple sequence repeat 
polymerase chain reaction. Archives of Otolaryngology: Head and Neck Surgery 129 96-100. (doi:10.1001/archotol.129.1.96)

Wiseman SM, Loree TR, Rigual NR, Hicks WL Jr, Douglas WG, Anderson GR \& Stoler DL 2003b Anaplastic transformation of thyroid cancer: review of clinical, pathologic, and molecular evidence provides new insights into disease biology and future therapy. Head and Neck 25 662-670. (doi:10.1002/hed.10277)

Wu G, Mambo E, Guo Z, Hu S, Huang X, Gollin SM, Trink B, Ladenson PW, Sidransky D \& Xing M 2005 Uncommon mutation, but common amplifications, of the PIK3CA gene in thyroid tumors. Journal of Clinical Endocrinology and Metabolism 90 4688-4693. (doi:10.1210/jc.2004-2281)

Xing M, Alzahrani AS, Carson KA, Shong YK, Kim TY, Viola D, Elisei R, Bendlova B, Yip L, Mian C, et al. 2015 Association between BRAF V600E mutation and recurrence of papillary thyroid cancer. Journal of Clinical Oncology 33 42-50. (doi:10.1200/JCO.2014.56.8253)

Xing M, Alzahrani AS, Carson KA, Viola D, Elisei R, Bendlova B, Yip L, Mian C, Vianello F, Tuttle RM, et al. 2013 Association between BRAF
V600E mutation and mortality in patients with papillary thyroid cancer. JAMA 309 1493-1501. (doi:10.1001/jama.2013.3190)

Yan J, Roy S, Apolloni A, Lane A \& Hancock JF 1998 Ras isoforms vary in their ability to activate Raf-1 and phosphoinositide 3-kinase. Journal of Biological Chemistry 273 24052-24056. (doi:10.1074/ jbc.273.37.24052)

Yeager N, Klein-Szanto A, Kimura S \& Di Cristofano A 2007 Pten loss in the mouse thyroid causes goiter and follicular adenomas: insights into thyroid function and Cowden disease pathogenesis. Cancer Research 67 959-966. (doi:10.1158/0008-5472.CAN-06-3524)

Zaballos MA \& Santisteban P 2013 FOXO1 controls thyroid cell proliferation in response to TSH and IGF-I and is involved in thyroid tumorigenesis. Molecular Endocrinology 27 50-62. (doi:10.1210/me.2012-1032)

Zhu Z, Gandhi M, Nikiforova MN, Fischer AH \& Nikiforov YE 2003 Molecular profile and clinical-pathologic features of the follicular variant of papillary thyroid carcinoma. An unusually high prevalence of ras mutations. American Journal of Clinical Pathology 120 71-77. (doi:10.1309/ND8D9LAJTRCTG6QD)

Received in final form 3 July 2017

Accepted 4 August 2017
๑) 2017 Society for Endocrinology Printed in Great Britain
Published by Bioscientifica Ltd. 